This item was submitted to Loughborough's Research Repository by the author.

Items in Figshare are protected by copyright, with all rights reserved, unless otherwise indicated.

\title{
A crystal plasticity study of cyclic constitutive behaviour, crack-tip deformation and crack-growth path for a polycrystalline nickel-based superalloy
}

\section{PLEASE CITE THE PUBLISHED VERSION}

http://dx.doi.org/10.1016/j.engfracmech.2011.04.006

PUBLISHER

(C) Elsevier

\section{VERSION}

AM (Accepted Manuscript)

\section{LICENCE}

CC BY-NC-ND 4.0

\section{REPOSITORY RECORD}

Lin, B., Liguo Zhao, and Jie Tong. 2019. "A Crystal Plasticity Study of Cyclic Constitutive Behaviour, Crack-tip Deformation and Crack-growth Path for a Polycrystalline Nickel-based Superalloy”. figshare.

https://hdl.handle.net/2134/10992. 
This item was submitted to Loughborough's Institutional Repository (https://dspace.lboro.ac.uk/) by the author and is made available under the following Creative Commons Licence conditions.

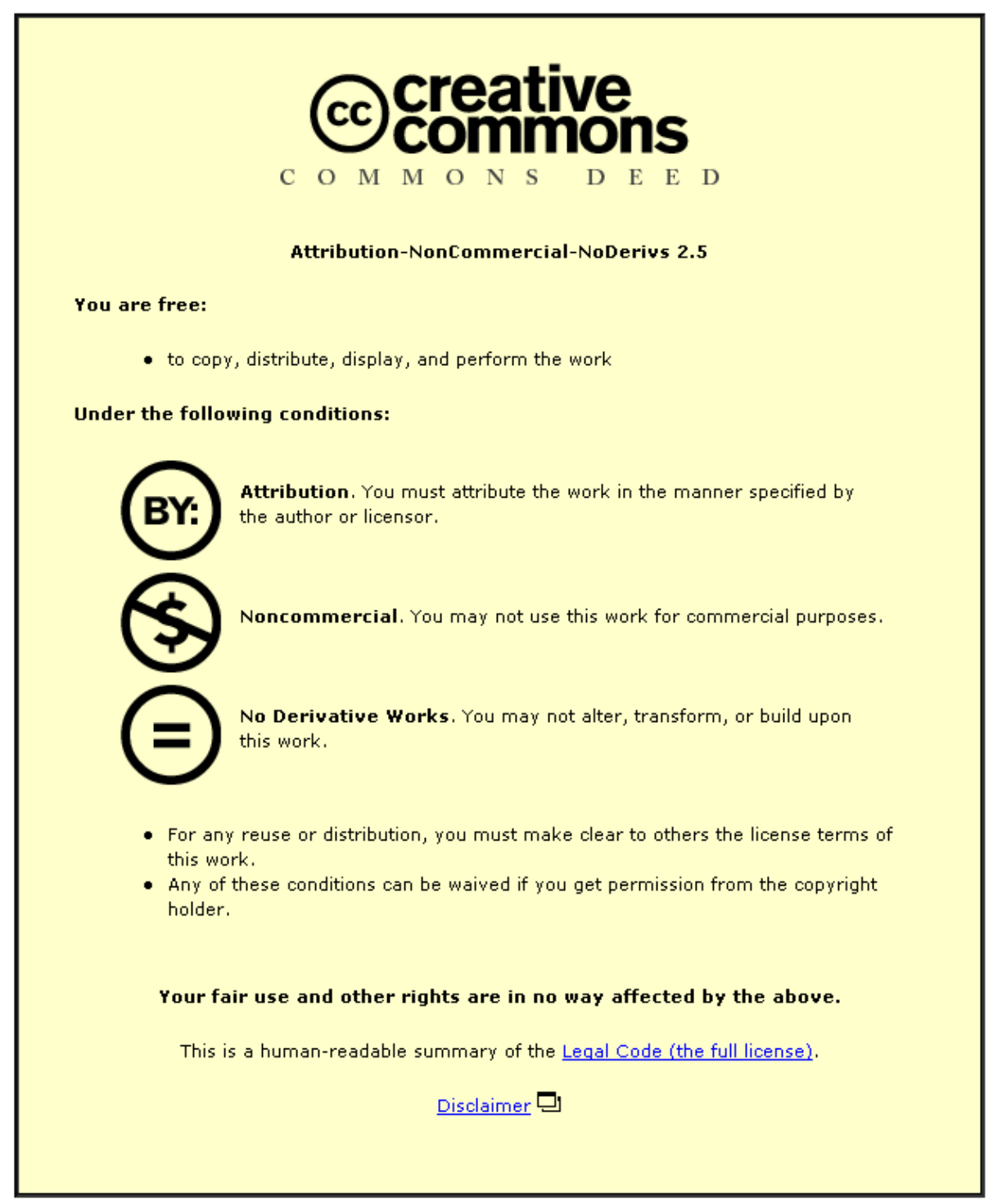

For the full text of this licence, please go to: http://creativecommons.org/licenses/by-nc-nd/2.5/ 
A Crystal Plasticity Study of Cyclic Constitutive Behaviour, Crack-Tip Deformation and

\title{
Crack-Growth Path for a Polycrystalline Nickel-Based Superalloy
}

\author{
B. Lin, L.G. Zhao, J. Tong \\ Department of Mechanical and Design Engineering, Anglesea Building, Anglesea Road \\ University of Portsmouth, Portsmouth, PO1 3DJ, the UK.
}

\begin{abstract}
Crystal plasticity has been applied to model the cyclic constitutive behaviour of a polycrystalline nickel-based superalloy at elevated temperature using finite element analyses. A representative volume element, consisting of randomly oriented grains, was considered for the finite element analyses under periodic boundary constraints. Strain-controlled cyclic test data at $650^{\circ} \mathrm{C}$ were used to determine the model parameters from a fitting process, where three loading rates were considered. Model simulations are in good agreement with the experimental results for stress-strain loops, cyclic hardening behaviour and stress relaxation behaviour. Stress and strain distributions within the representative volume element are of heterogeneous nature due to the orientation mismatch between neighboring grains. Stress concentrations tend to occur within "hard" grains while strain concentrations tend to locate within "soft" grains, depending on the orientation of grains with respect to the loading direction. The model was further applied to study the near-tip deformation of a transgranular crack in a compact tension specimen using a submodelling technique. Grain microstructure is shown to have an influence on the von Mises stress distribution near the crack tip, and the
\end{abstract}


gain texture heterogeneity disturbs the well-known butterfly shape obtained from the viscoplasticity analysis at continuum level. The stress-strain response near the crack tip, as well as the accumulated shear deformation along slip system, is influenced by the orientation of the grain at the crack tip, which might dictate the subsequent crack growth through grains. Individual slip systems near the crack tip tend to have different amounts of accumulated shear deformation, which was utilised as a criterion to predict the crack growth path.

Keywords: Crystal plasticity, Representative volume element, Submodel, Crack-tip deformation, Finite element.

\section{Nomenclature}

$\begin{array}{ll}\boldsymbol{F}, \boldsymbol{F}^{\mathrm{e}}, \boldsymbol{F}^{\mathrm{p}} & \text { total, elastic and plastic deformation gradient } \\ \boldsymbol{L}^{\mathrm{p}} & \text { inelastic velocity gradient } \\ \alpha & \text { slip system } \\ \dot{\gamma}^{\alpha} & \text { shear strain rate of slip system } \alpha \\ \boldsymbol{m}^{\alpha}, \boldsymbol{n}^{\alpha} & \text { slip direction and slip plane normal for slip system } \alpha \\ S^{\alpha} & \text { slip resistance of slip system } \alpha \\ S_{0}^{\alpha} & \text { initial slip resistance of slip system } \alpha \\ B^{\alpha} & \text { back stress } \\ \kappa & \text { Boltzmann constant } \\ \tau^{\alpha} & \text { resolved shear stress on slip system } \alpha \\ \theta & \text { absolute temperature }\end{array}$




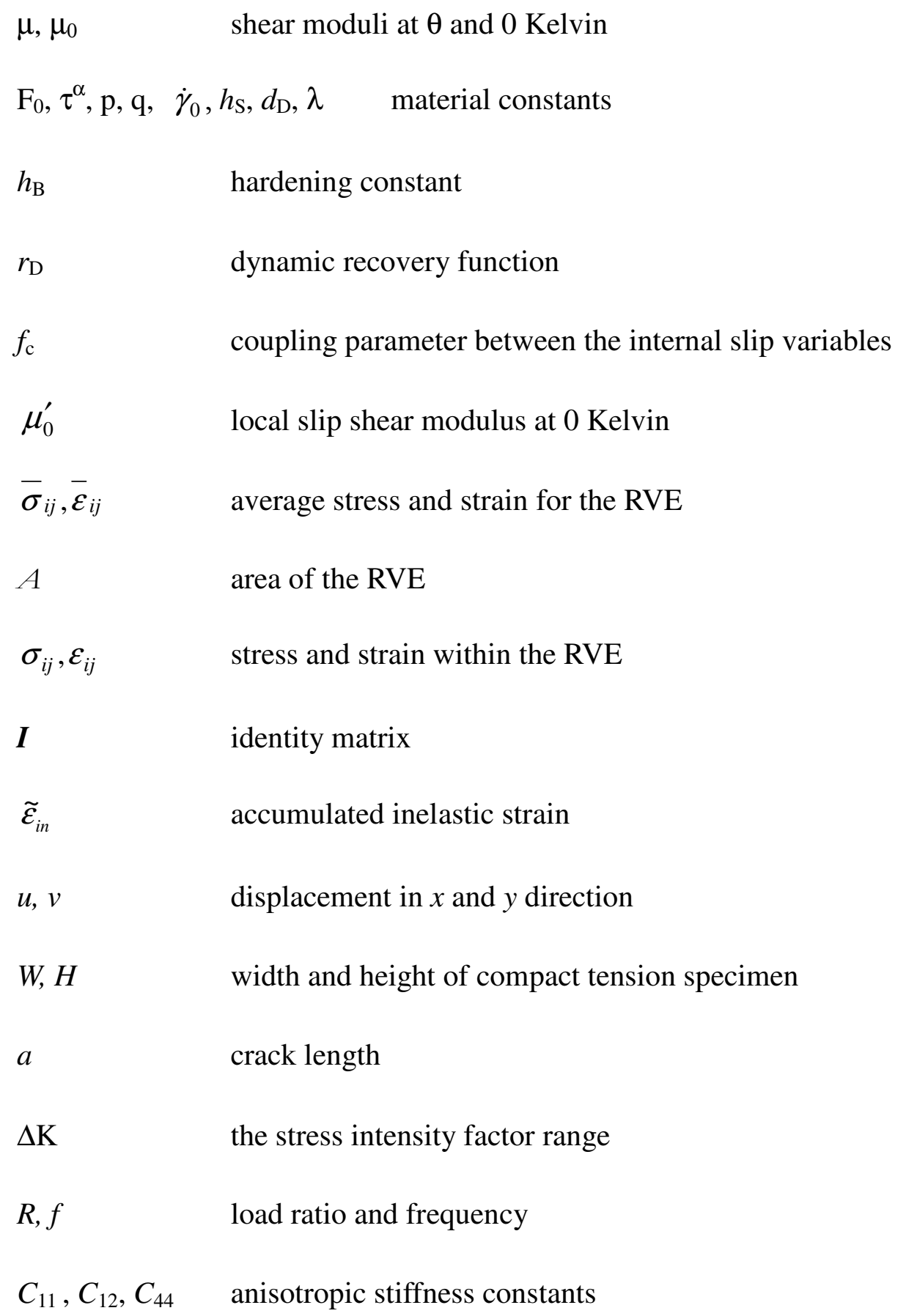


through a powder metallurgy process for application in the latest aero engines designed to have higher overall pressure ratios, compressor discharge temperatures and rotational speeds. Constitutive, fatigue and creep behaviour of RR1000 at high temperature have been systematically studied at Portsmouth, and the data and the models are already available for validation of the material for turbine discs [1-9].

However, the work has been so far limited to continuum level which is incapable of dealing with material micro-structural features and the influence of these features on the mechanical behaviour of the material. Alloy RR1000 is a face-centred-cubic (f.c.c.) polycrystalline metallic alloy with a fine grain microstructure. There is a mismatch of mechanical properties between grains due to the orientation difference. This mismatch could raise the stress levels locally to evoke crystallographic plastic deformation and to prompt microcrack initiation. A review of literature shows that the physically-based crystal plasticity theory has been generally used to describe the mechanical behaviour of materials at grain level. With the assistance of the finite element (FE) method, the theory is able to predict the global and local stress-strain response [10-15], the evolution of crystallographic grain texture $[10,16]$ and micro-structural crack nucleation [17-19] in polycrystalline materials under monotonic, creep and fatigue loading conditions. Recently, application of the theory has also been extended to polycrystalline nickel superalloy, where material microstructure was considered as one of the major factors influencing the fatigue and creep properties of the material. For instance, Dunne et al. [20] used a simplified crystal plasticity model to study the low cycle fatigue crack nucleation in a directionally solidified nickel alloy. The experimentally observed sites 
of crack nucleation near a free surface matched those of the persistent slip bands predicted from the crystal plasticity model. Shenoy et al. [21] formulated a rate-dependent microstructure-sensitive crystal plasticity model for correlating the mechanical behaviour of a polycrystalline Ni-based superalloy IN 100 at $650^{\circ} \mathrm{C}$. The model has the capability to capture the first order effects on the stress-strain response due to grain size, precipitate size distribution, precipitate volume fraction and dislocation density for each slip system.

Very recently, we have carried out crystal plasticity modelling of the global and local cyclic deformation for alloy RR1000, where the simulations compare well with experimental results for stress-strain loops, cyclic hardening behaviour and stress relaxation behaviour [22]. Stress and strain contour plots showed heterogeneous distribution due to orientation and property mismatch between neighboring grains. However, the work of Lin et al. [22] considered the in-plane grain orientation only, represented by the random variation of a single Euler angle, which is unable to capture the grain orientations properly. Such limitation has been overcome in the present study by using three randomly assigned Euler angles to represent the grain orientation in three dimensions. As illustrated in Fig.1, for a 150-grain RVE, there is only a circle in the pole figure (Figs.1a and 1c) and a line in the inverse pole figure (Fig.1e) when one Euler angle is used to represent the in-plane grain orientation, while random distribution of grain orientations can be seen in the pole and inverse pole figures (Figs.1b, $d$ and $f$ ) if three Euler angles are adopted instead.

In addition, from a macroscopic point of view, fatigue life consists of crack initiation and 
propagation phases. Crack initiation phase can be divided into micro-structurally short crack initiation and subsequent micro-structurally short crack propagation, both of which are strongly influenced by local micro-structural features, such as crystallographic orientations, inclusions, voids, grain boundaries and material phases [23-25]. For crack propagation phase, different size and crystallographic orientation of the grains may also increase, decrease or arrest the crack growth [26-29]. Also, grain orientation mismatch leads to the change of slip plane across the grain boundaries [30], resulting in a zig-zag pattern for crack growth [31]. In terms of modelling, a combination of crystal plasticity and simplified grain-structure modelling has been applied to study crack tip displacements, crack tip plasticity and crack opening/closure stress [26, 32-35]. It was concluded that both crack tip opening and sliding displacements contribute to the crack growth [26], and plastic zone size significantly depends on the crystallographic orientation [32]. In recent years, attempts have been made to account for random grain shapes by either transfering of the digital measurement to the FE model or using Voronoi tessellation [35, 36], which has been mostly focused on short cracks. For a major crack, Sreeramulu et al. [37] studied the mode I and II crack tip fields in polycrystalline solids under plane-strain and small-scale yielding conditions. It was found that significant texture evolution occurs close to the notch tip, which profoundly influenced the stress and plastic strain distributions. Also, the anisotropy due to cold rolling gave rise to a higher magnitude of plastic strain near the tip. However, their polycrystalline plasticity formulation was based on Taylor-type homogenization and did not consider the explicit influence of grain microstructure. 
In this paper, a pilot crystal plasticity study of constitutive behaviour, crack tip deformation and crack growth path was carried out for a nickel-based superalloy RR1000 under fatigue loading conditions at $650^{\circ} \mathrm{C}$. The work aims to provide a micro-mechanics based understanding of cyclic deformation behaviour for the material. In particular, the three-dimensional nature of grain orientations was considered in the cyclic deformation simulation, which has overcome one of the major limitations of our recent work Lin et al. [22] and similar work in the literature. Furthermore, using an FE submodelling technique, the crystal plasticity model was applied to study explicitly the effects of grain microstructure on the near-tip deformation of a primary crack, which has not yet been reported. Accumulated shear deformation was computed for individual slip systems near the crack tip and utilised, for the first time, to predict the influence of grain orientation on the crack path. A similar criterion based on cumulative plastic strain has been used in Dunne et al. [20] and also discussed in McDowell and Dunne [38], but these were focused mainly on fatigue crack nucleation. Based on the key results of the present work, discussions were made regarding the heterogeneous inelastic deformation within the RVE and the effect of grain orientation on crack-tip deformation. The limitations of the work were also discussed.

\section{Crystal plasticity formulation}

The framework of crystal plasticity theory relies on the multiplicative decomposition of the total deformation gradient $\boldsymbol{F}$ into an elastic $\left(\boldsymbol{F}^{\mathrm{e}}\right)$ part and a plastic $\left(\boldsymbol{F}^{\mathrm{p}}\right)$ part [39]. The plastic component $\boldsymbol{F}^{p}$ is calculated from the inelastic velocity gradient $\boldsymbol{L}^{p}$ according to [39]:

$$
\boldsymbol{L}^{\boldsymbol{p}}=\dot{\boldsymbol{F}}^{\boldsymbol{p}} \boldsymbol{F}^{\boldsymbol{p}^{-1}}=\sum_{\alpha=1}^{\boldsymbol{n}} \dot{\gamma}^{\alpha}\left(\boldsymbol{m}^{\alpha} \otimes \boldsymbol{n}^{\alpha}\right)
$$


where $\dot{\gamma}^{\alpha}$ is the shear strain rate on the slip system $\alpha, \boldsymbol{m}^{\alpha}$ and $\boldsymbol{n}^{\alpha}$ are the slip direction and the slip plane normal, respectively.

With the incorporation of two scalar state variables per slip system, i.e., slip resistance $\left(S^{\alpha}\right)$ and back stress $\left(B^{\alpha}\right)[40]$, the flow rule is expressed as an exponential function of the resolved shear stress on the slip system:

$$
\dot{\gamma}_{\alpha}=\dot{\gamma}_{0} \exp \left[\frac{-F_{0}}{\kappa \theta}\left\langle 1-\left\langle\frac{\left|\tau^{\alpha}-B^{\alpha}\right|-S^{\alpha} \mu / \mu_{0}}{\hat{\tau}_{0} \mu / \mu_{0}}\right\rangle^{p}\right\rangle^{q}\right] \operatorname{sgn}\left(\tau^{\alpha}-B^{\alpha}\right),
$$

where $\kappa$ is the Boltzmann constant, $\tau^{\alpha}$ is the resolved shear stress on the slip system $\alpha, \theta$ the absolute temperature, $\mu$ and $\mu_{0}$ the shear moduli at $\theta$ and 0 Kelvin, respectively, and $\mathrm{F}_{0}, \hat{\tau}_{0}, \mathrm{p}$, $\mathrm{q}$ and $\dot{\gamma}_{0}$ are material constants. The brackets imply that $\langle x\rangle=x$ for $x>0$ and $\langle x\rangle=0$ for $x \leq 0$.

The two internal variables, the slip resistance in each slip system, $S^{\alpha}$, and the back stress, $B^{\alpha}$, are introduced at the slip system level, which represent the state associated with the current dislocation network. The slip resistance on a generic slip system, associated with the dislocation density along that slip system (i.e., self-hardening), is assumed to evolve according to the following relation, starting at an initial value of $S_{0}$ [41],

$$
\dot{S}^{\alpha}=\left[h_{S}-d_{D}\left(S^{\alpha}-S_{0}^{\alpha}\right)\right]\left|\dot{\gamma}^{\alpha}\right|
$$


where the first and second terms are static and dynamic recovery terms associated with the material constants $h_{\mathrm{S}}$ and $d_{\mathrm{D}}$, respectively.

The back stress is representative of the internal stress state arising due to dislocations bowing between obstacles which can be either precipitates or other dislocations. The back stress evolves according to a standard hardening-dynamic recovery format [41],

$$
\dot{B}^{\alpha}=h_{B} \dot{\gamma}^{\alpha}-r_{D} B^{\alpha}\left|\dot{\gamma}_{\alpha}\right|
$$

where $h_{\mathrm{B}}$ is a hardening constant, and $r_{\mathrm{D}}$ is a dynamic recovery function which introduces the inherent dependency between the slip resistance and back stress and may be expressed as [40]:,

$$
r_{D}=\frac{h_{B} \mu_{0}}{S^{\alpha}}\left\{\frac{\mu_{0}^{\prime}}{f_{c} \lambda}-\mu\right\}^{-1}
$$

where $f_{\mathrm{c}}$ is a coupling parameter between the internal slip variables and $\mu_{0}^{\prime}$ the local slip shear modulus at 0 Kelvin.

The crystallographic formulation was implemented numerically into the finite element (FE) code ABAQUS [42] within the framework of large strain kinematics via a user-defined material subroutine (UMAT), where the fully implicit (Euler backward) integration algorithm was adopted [41, 43, 44]. 
As addressed in Dennis [43], two slip system families are commonly required to describe consistently the inelastic behaviour of f.c.c. Ni-base superalloys at high temperature, namely octahedral $(\{111\}<110>)$ and cubic $(\{100\}<110>)$ slip. Octahedral slip happens on the closely packed slip plane while cubic slip occurs on less closely packed slip plane. Consequently, two sets of material parameters (see Section 4 for parameter determination) are required to describe the octahedral and cubic slip systems respectively [43].

\section{Finite element model}

\subsection{RVE model}

As shown in Fig.2a (from Stöcker et al. [45]), polycrystalline alloy RR1000 has a fine grain structure with an average grain size of $4.76 \mu \mathrm{m}$ and random crystallographic orientation. To study the mechanical deformation at the grain level, a plane-strain representative volume element (RVE) is used to represent the global material behaviour, which was constructed using the Voronoi tessellation technique [46]. Each grain was assumed to have random orientation represented by three randomly assigned Euler angles (see the inverse pole figure in Fig.1f). Periodic boundary conditions are applied, which enforce parallel deformation of opposite edges $[47,48]$ and can be expressed as:

$$
\begin{aligned}
& u(C D)-u(A B)=u(C)-u(A) \\
& v(B D)-v(A C)=v(B)-v(A)
\end{aligned}
$$

where $u(\mathrm{AB})$ and $u(\mathrm{CD})$ are the $x$-direction displacements for edges $\mathrm{AB}$ and $\mathrm{CD} ; v(\mathrm{BD})$ and $v(\mathrm{AC})$ are the $y$-direction displacements for edges $\mathrm{BD}$ and $\mathrm{AC} ; u(\mathrm{C})$ and $u(\mathrm{~A})$ are the 
$x$-direction displacements for nodes $\mathrm{A}$ and $\mathrm{C} ; v(\mathrm{~A})$ and $v(\mathrm{~B})$ are the $y$-direction displacements of nodes A and B. A sketch of the deformed shape, which satisfies the periodic boundary condition, has been illustrated by dashed lines in Fig.2b. To remove the rigid body motion, the vertex A was fixed in both $x$ and $y$ directions, and $\mathrm{B}$ and $\mathrm{C}$ were fixed in the $x$ and $y$ direction, respectively. A displacement was applied to vertex B in the y-direction to simulate the uniaxial strain-controlled loading condition.

The RVE was meshed into first-order four-node plane strain elements with full integration. When large strain gradients or strain discontinuities are expected in a solution, such as in plasticity analysis at large strains, which is the case for the present work, first-order elements are usually recommended [42]. To obtain the global response of the material, homogenization based on averaging theorem over the RVE area was adopted [49], which was calculated via the following area integral:

$$
\begin{aligned}
& \bar{\sigma}_{i j}=\frac{1}{A} \int_{A} \sigma_{i j} d A \\
& \bar{\varepsilon}_{i j}=\frac{1}{A} \int_{A} \varepsilon_{i j} d A
\end{aligned}
$$

where $\bar{\sigma}_{i j}$ and $\bar{\varepsilon}_{i j}$ are the average stress and strain for RVE model, $A$ is the area of the RVE, $\sigma_{i j}$ and $\varepsilon_{i j}$ are the stress and strain within the RVE.

The area integrals in (8) and (9) were computed using the Gauss integration algorithm as used in ABAQUS. A post-processing program was written in Fortran to obtain the stress and strain values for all the FE integration points and then perform the Gauss integration to work out the global stress and strain response. 
Using the crystal plasticity framework presented in the above section, FE analyses were carried out for four RVE models, containing 50, 100, 150 and 200 grains respectively, under monotonic tensile loading condition up to $5 \%$ strain at a strain rate of $0.005 \% / \mathrm{s}$, where the convergence of stress-strain curve was achieved at 150 grains. A mesh-sensitivity study was also carried out for the 150-grain model, where meshes with 921, 1450 and 4315 elements were evaluated. The results showed that the stress-strain curves reached a good convergence for the 1450-element mesh. It was also verified that the global stress in the $x$-direction and the global in-plane shear stress are negligible, which confirms the predominant uniaxial strain-controlled loading condition of the RVE in the $y$-direction. A convergence study was also carried out at grain level, where both the stress/strain distribution of the RVE and the stress-strain response for individual grains were examined for three different meshes (921, 1450 and 4315 elements, respectively) and a good convergence was achieved for the 1450-element mesh. For further validation, a pseudo three-dimensional (3D) RVE, which allows us to consider the deformation of the slip systems in a realistic three dimension, has been constructed for simulation, where the front and the back surfaces were constrained fully to represent the plane strain situation, i.e., the nodes were not allowed to move in the depth direction. Given the same random orientation for all the grains, the simulated stress-strain response is almost the same as that for the two-dimensional (2D) plane-strain RVE.

In the present work, evaluation of RVE size and mesh sensitivity were purely based on FE analyses, which led us to adopt the 150-grain RVE. Further analyses have been carried out for 
RVEs with 50, 100 and 150 grains by considering 10 different sets of grain orientations. The stress-strain curves showed that the scatter is almost negligible for the 150-grain RVE. In what follows, FE analyses were performed for the RVE with 150 grains and 1450 finite elements to evaluate the global and local cyclic deformation for alloy RR1000 at $650^{\circ} \mathrm{C}$.

It should be pointed out that a preliminary set of material parameters was initially used to determine the adequate grain number and element number for RVE model. After the final model parameters were fitted (see Section 4), FE analyses were run again to check the convergence and the results presented in this paper were, in fact, obtained using the final set of parameters, as given in Table 1 .

\subsection{Submodel for a transgranular crack}

A standard CT specimen (width $W=26 \mathrm{~mm}$ and height $H=15.6 \mathrm{~mm}$ ) was considered for crack tip deformation analyses. The finite element mesh for the whole specimen, shown in Fig.3a, consists of four-node, first-order elements with full integration. Cyclic load, with the stress intensity factor range $\Delta \mathrm{K}=25 \mathrm{MPam}^{1 / 2}$ and a load ratio $\mathrm{R}=0.1$, was applied to a rigid pin fitted into the hole of the specimen. The rigid pin and the hole of specimen were treated as a pair of contact surfaces in ABAQUS [42]. The crack length was chosen to be $a=13 \mathrm{~mm}$, i.e., $a / W=0.5$.

FE submodelling was adopted to study the dependence of crack tip deformation on the grain microstructure near the crack tip. As shown in Fig.3b, the submodel was constructed near the 
crack tip and contains 150 grains with randomly assigned orientations, where the loading was prescribed by the displacement of its boundaries from the global model analyses (ABAQUS). A transgranular crack across a couple of grains was introduced in the submodel. The grains in the vicinity of the crack tip are identified in the inverse pole figure, as illustrated in Fig.4.

The deformation of the submodel follows the crystal plasticity formulation as given in Section 2, while the global model was described by a viscoplastic constitutive formulation [50], as adopted for RR1000 [6], where both isotropic and kinematic hardening variables are considered during the transient and saturated stages of cyclic responses. The viscoplasticity model has also been programmed into a user-defined material subroutine (UMAT), using a fully implicit integration and the Euler backward iteration algorithm [7], and implemented in the finite element software ABAQUS [42]. The whole procedure starts with the FE analyses for global model followed by the submodelling analyses.

To evaluate the mesh sensitivity, three meshes have been generated, corresponding to an element sze of $0.40 \mu \mathrm{m}, 0.20 \mu \mathrm{m}$ and $0.13 \mu \mathrm{m}$, respectively, near the crack tip. The stress and strain response, averaged over a distance of $0.40 \mu \mathrm{m}$ (about one tenth of the average grain size) ahead of the crack tip, confirms a good convergence for the $0.20 \mu \mathrm{m}$ mesh which has been used for the crack tip deforamtion analyses.

It should be pointed out here that the submodelling analyses followed the procedure in ABAQUS, which only satisfies the displacement continuity at the interface between the 
submodel and global model. As traction continuity is not ensured at the interface, hence the results near the interface should be treated as approximate. Nevertheless, as the crack tip is reasonably away from the interface, such influence on the crack-tip field would be limited, which has been confirmed by the same $\Delta \mathrm{K}$ value obtained from the submodelling analyses.

\section{Modelling of Cyclic Constitutive Behaviour}

\subsection{Parameter determination}

The crystal-plasticity model was calibrated by fitting the stress-strain response of the strain-controlled cyclic tests at three different strain rates $(0.5 \% / \mathrm{s}, 0.05 \% / \mathrm{s}$ and $0.005 \% / \mathrm{s})$ [3]. Prior to the fitting process, material constants were estimated from the literatures. For instance, the full model parameters are already available for CMSX4 nickel single crystals $[41,43,44]$, which serve as a general guideline on the initial estimations. The calibration of material constants also involves certain constraints, which were imposed as the ranges of target values based on published work. For example, the value of $p$ and $q$ were recommended to be $0<\mathrm{p}<1$ and $1<\mathrm{q}<2$ [10], which greatly facilitated the calibration process. Also, to improve the efficiency of the fitting process, a sensitivity analysis of parameters with respect to the stress-strain response was conducted in the first stage of calibration. Given all of the crystal plasticity parameters that needed to be calibrated, it is known that some of them have specific influence on the stress-strain response, such as that the parameters $p$ and $q$ mainly influence the shape of the loops.

The whole process began with fitting the monotonic stress-strain curves and the first cyclic 
loops for all three loading rates. During this process, the main target was to identify the material parameters $\mathrm{p}, \mathrm{q}$ and $\hat{\tau}_{0}$, which control the rate sensitivity, and work out their sensible values. Then, efforts were made to improve the cyclic hardening simulation, which involves re-calibration of some of the critical material parameters which control the cyclic hardening behaviour. In this process, the major influencing parameters were found to be a combination of the parameters $f_{\mathrm{C}}$ and $h_{\mathrm{S}}$.

Following each simulation, the resulting stress values at each strain point were compared with the experimental data, the magnitude of the difference was considered in an error function (objective function) over the history. Optimization was carried out until the error was minimized. The final parameter values determined by the fitting process are listed in Table 1 for both octahedral and cubic slip systems. Other fitted parameters include the coefficient $\lambda=0.85$ and the shear modulus at 0 Kelvin $\mu_{0}=192 \mathrm{GPa}$. Anisotropic stiffness constants were taken as $C_{11}=166.2 \mathrm{GPa}, C_{12}=66.3 \mathrm{GPa}$ and $C_{44}=138.2 \mathrm{GPa}$, which give a global Young's modulus of $190 \mathrm{GPa}$ for alloy RR1000 at $650^{\circ} \mathrm{C}$ and matches the experimental measurement [3].

\subsection{Stress-strain response}

The simulated stress-strain responses for monotonic and the first cycle of fatigue loading are shown in Fig.5 for the strain rate of $0.05 \% / \mathrm{s}$, with a direct comparison against the experimental data $[3,6]$. Clearly, the model simulations agree very well with the test data. 
The stress response and the shape of hysteresis loops were both well captured by the crystal-plasticity-based FE analysis of the RVE.

Cyclic hardening behaviour was presented in Fig.6 by plotting the stress amplitude as a function the number of cycles for the $0.05 \% / \mathrm{s}$ strain-loading rate. Test data $[3,6]$ were included for a direct comparison, where a good match is demonstrated. For the nickel alloy RR1000, cyclic deformation seems to reach saturation after about 25 cycles. As shown in Fig.7, simulated stress-strain loops at saturation also agree very well with the experimental results.

As an independent evaluation for the model, the same parameters were also used in simulations for cyclic uniaxial strain-controlled histories with 100-second hold time superimposed at both the maximum and minimum strain levels. The simulated stress relaxation during the strain hold periods are shown in Fig. 8 for strain range $=2.0 \%$ and strain rate $=0.5 \% / \mathrm{s}$, which are again in good agreement with the experimental data [3].

\subsection{Stress-strain distribution}

Figs. 9 and 10 show the contour plots of the normal stress and strain in the $y$-direction at the maximum strain level of the $25^{\text {th }}$ cycle for the $0.05 \% / \mathrm{s}$ loading rate case, where heterogeneous stress and strain distributions are observed. The maximum value of the local stress $(1696 \mathrm{MPa})$ is about 1.4 times the global stress $(1215 \mathrm{MPa})$ and the maximum local strain $(1.7 \%)$ is about 1.7 times the global strain (1\%). Stress and strain concentrations are 
located in different grains. A number of grains with high stress and strain concentrations are selected and their orientations are identified and presented in the inverse pole figure, respectively. The grains with high strain concentrations are orientated towards the [001] in the inverse pole figure (see Fig.10b), while those with high stress concentrations tend to locate away from [001] orientation (towards [101] and [111]) in the inverse pole figure (see Fig.9b). The highest strain concentrations are located within the "soft" grains, which have low strain hardening in the stress-strain response (see Fig.11). On the other hand, the highest stress concentrations are typically located within the "hard" grains, which have high strain hardening in the stress-strain response (see Fig.11). As demonstrated in Fig.11, the stress-strain loops are much wider for the soft grains than those for the hard grains, indicating more inelastic deformation in the soft grains. Also most stress and strain concentrations are located at the triple or multiple points due to the mismatch of the mechanical properties of multiple grains. Here, the normal stress and strain in the y-direction, instead of the equivalent stress-strain measures, were used to evaluate the hardening behaviour of individual grain, as equivalent stress-strain measures have only absolute values and are considered less indicative for damage analysis than the normal stress and strain. Also, the normal (in the x-direction) and shear stress-strain responses for individual grains are much smaller than that in the y-direction.

\section{Modelling of crack-tip deformation and crack path}

\subsection{Stress-strain response near the crack tip}

As shown in Fig.12a, contour plot of the von Mises stress show stress concentrations near the 
crack tip confirms the well-known butterfly shape for viscoplastcity simulation. However, for crystal plasticity simulation, grain microstructure does have an influence on the Mises stress contour zone which does not have the butterfly shape (Fig.12b). The stress concentration zone obtained from the crystal plasticity analyses seems to be of an arbitrary shape and is less severe than that obtained from the visco-plasticity analyses. Shape and size of the stress contour zone are clearly affected by the heterogeneity of the grain microstructure. This could be due to the presence of mechanical property mismatch of individual grains which results in the re-distribution of the local stress concentration near the crack tip. Further FE analyses were also carried out for the RVE by assigning a single orientation to all grains, which is equivalent to a single crystal material. The contour plot of von Mises stress generally shows a highly distorted and asymmetric butterfly shape, indicating the significance of grain orientation in crack tip field [51, 52].

The stress-strain response in the y-direction, averaged over a distance of $0.40 \mu \mathrm{m}$ ahead of the crack tip, is shown in Fig.13, in a comparison with those obtained from the continuum viscoplasticity analyses. For both cases, the cyclic stress-strain loops remain open and exhibit a so-called ratchetting phenomenon, where the plastic deformation during the loading portion is not balanced by an equal amount of yielding in the reverse loading direction. By changing the orientation of the crack-tip grain to that for grain $1^{\prime}$ and $1^{\prime \prime}$, as shown in the inverse pole figure in Fig.4, the stress-strain loops near the crack tip become different (see Fig.14), indicating the influence of grain orientation. 


\subsection{Shear deformation along slip planes near the crack tip}

The shear deformation along individual slip system near the crack tip has been extracted from the FE results, which is shown to vary according to the slip system. It turns out that four slip systems appear to have the most notable amount of shear deformation accumulated in four cycles, which include three octahedral slip systems (111)[1-10], (1-11)[-101] and (1-11)[110] and one cubic slip system (100)[0-11]. The 2D in-plane traces of these four slip systems are shown in Fig.15a, and the accumulated shear strain are plotted in Fig.15b for each slip system. The slip traces illustrated in Fig. $15 \mathrm{~b}$ are the projections of the 3D slip systems onto the 2D crack plane (perpendicular to the crack growth direction).

Within four cycles, the cubic slip system (100)[0-11] has accumulated the maximum amount of shear deformation. If the accumulated slip was used as the crack growth criterion, the crack will grow along the trace of the cubic slip system (100)[0-11], as sketched in Fig.15a. By changing the orientation of the crack-tip grain to that for grain 1' and 1", as shown in the inverse pole figure in Fig.4, crack growth will then follow the trace for the octahedral slip system (-1-11)[-110] and the cubic slip system (111)[1-10], respectively, which happen to have the maximum amount of accumulated slip (see Fig.16).

\subsection{Prediction of crack growth path}

Studies of fatigue of polycrystalline alloys at grain level indicated that crack nucleation and subsequent transgranular growth tend to follow the slip planes due to the shear deformation associated with the slip systems [e.g., 27, 30, 35, 53]. Along the same line, here it was 
proposed that crack growth in the grain interior will follow the direction of slip trace with the maximum accumulated slip, which can be computed from the crack-tip deformation analyses. Once the slip trace was identified, the crack length was immediately increased to the grain boundary along the slip system, representing a series of stationary cracks. As the material has a fine grain micro-structure, it seems plausible to assume that crack will grow along the slip trace without changing to another direction within the gain. Also, for polycrystalline material, experiment observations show that crack growth tend to follow the slip plane in each grain and a change of crack growth behaviour mostly happens when crossing the grain boundaries due to the change of favourable slip planes [27, 30].

When the crack meets the grain boundary, the model was re-meshed for further finite element analysis, from which the slip trace with the maximum amount of accumulated slip was obtained to determine the crack growth path into the next grain. The size for the crack tip mesh near the grain boudary is about $0.6 \mu \mathrm{m}$ and mesh sensitivity results show that the slip trace with the maximum amount of shear deformation remains unchnaged with mesh refinement.

Two submodels with different sets of random orientation were considered and the predicted crack growth paths are shown in Fig.17, with details of the identified slip system for each crack growth segment. The loading condition is the same as that used for crack tip deformation analyses, namely, the stress intensity factor range $\Delta \mathrm{K}=25 \mathrm{MPam}^{1 / 2}$, load ratio $\mathrm{R}$ $=0.1$ and frequency $f=0.25 \mathrm{~Hz}$. The level of $\Delta \mathrm{K}$ is well below the fracture toughness for 
alloy RR1000 (in the range of $100 \mathrm{MPam}^{1 / 2}$ ). A closer look at the zig-zag path, predicted from the maximum shear deformation criterion, seems to suggest that the overall crack path tends to follow the major growth direction which is perpendicular to the external load.

\section{Discussions}

\subsection{Cyclic deformation}

As shown in the present work, in addition to the global mechanical behaviour, the crystal plasticity model is capable of predicting the heterogeneous nature of local stress and strain behaviour, which is of great significance for prediction of crack initiation. Local stress and strain concentrations are located in the so-called "hard" and "soft" grains, respectively, and the stress-strain loops for the "soft" grains are much wider than those for the "hard" grains (Fig.11), indicating more inelastic deformation in the soft grains. The "soft" and "hard" grains refer to the different stress-strain behaviour for individual grains due to the difference in the orientation of the grains with respect to the loading direction. In the present work, the grain orientation with respect to the loading direction may be identified in the inverse pole figure drawn in the loading direction (Fig.9b and 10b). FE analyses were also carried out for the RVE loaded in the x-direction, and the corresponding inverse pole figure for the identified "hard" and "soft" grains confirms that soft grain tends to locate in the [001] orientation and hard grains tends to locate away from [001] orientation, which is consistent with that for the y-direction loading. This information could be further explored as a criterion for prediction of crack nucleation under low cycle fatigue. 
A contour plot of the accumulated inelastic strain at the maximum strain level of the $25^{\text {th }}$ cycle is shown in Fig. 18 for the RVE loaded at a strain rate $\mathrm{d} \varepsilon / \mathrm{dt}=0.005 \% / \mathrm{s}$ and strain range $\Delta \varepsilon=2 \%$, which has the same pattern as the strain distribution (see Fig.10). The accumulated inelastic strain is referred to the accumulation of equivalent inelastic strain, whose rate is defined as $\dot{\widetilde{\mathcal{E}}}_{\text {in }}=\sqrt{\frac{2}{3}\left(\dot{\boldsymbol{F}}^{P}-\boldsymbol{I}\right):\left(\dot{\boldsymbol{F}}^{P}-\boldsymbol{I}\right)}$, where $\dot{\boldsymbol{F}}^{P}$ is the rate of inelastic deformation gradient and $\boldsymbol{I}$ is the identity matrix. In Fig.18, only some localized inelastic deformation bands can be observed, which may prompt fatigue crack initiation and propagation, leading to transgranular fracture during crack growth. Cyclic deformation bands normally consist of a few connected grains which have a high level of accumulated inelastic strain after a number of loading cycles. However, at a low strain level (up to $1 \%$ ), deformation bands are highly localized within individual grains, as shown in Fig.18, which is also true for the von Mises equivalent strain. FE analyses were carried out for the RVE cyclically loaded at a high strain level, up to $10 \%$ at a strain rate of $0.005 \% / \mathrm{s}$ and strain ratio of -1 , and the grey-scale contour plot of the von Mises equivalent strain at the maximum strain level of the $2^{\text {nd }}$ cycle (Fig.19) clearly shows the cyclic deformation bands inclined at 45 or 135 degree with respect to the loading direction, similar to that observed in Kovač et al. [15] for monotonic loading condition. This is also the case for the contour plot of the accumulated inelastic strain $\widetilde{\varepsilon}_{i n}$.

Experimental observations have showed a direct link between the fatigue crack initiation and the localized slip bands predicted by crystal plasticity modelling for aluminium [17], titanium alloys $[19,54]$ and nickel alloys [20]. These results seem to support the role of slip bands in promoting fatigue crack nucleation. As reported, at grain level fatigue crack could nucleate 
from either hard $[19,54]$ or soft $[17,20]$ grains, which seems to depend on material properties and loading conditions. For alloy RR1000, which has superior high-temperature mechanical properties and toughness, fatigue crack initiation at $650^{\circ} \mathrm{C}$ is most likely to be associated with the accumulated inelastic deformation in the soft grains. At grain level, slip-induced deformation tends to accumulate within the soft grains (see Figs.10 and 18) and hence prompting crack nucleation from those soft grains due to the severe inelastic strain concentrations.

\subsection{Crack-tip deformation}

Crystal plasticity model is able to study the effects of the grain orientation on crack tip deformation and associated crack growth, an advantage over the continuum mechanics approach [55]. In addition to the near-tip stress-strain response (Figs.13 and 14), the accumulated shear deformation along the slip system which has the maximum amount of accumulated slip (see Figs.15 and 16) is compared in Fig.20 for the three differently orientated grains at the crack tip (Fig.4). The maximum amount of slip accumulation is different due to the different grain orientation, and, in 4 cycles, it reached 1.8, 0.8 and 0.9 for grain 1, 1' ad 1", respectively. As seen from Figs.13, 14 and 20, near the crack tip, both the stress-strain response and the accumulated shear deformation along the slip system vary according to the orientation of the crack-tip grain, which might indicate variable crack growth rates should the crack chose to grow through different grains. The present work has also shown that the slip-related shear deformation is different for different slip systems (Fig.15b). The amount of slip depends on the orientation of the grain at the crack tip, which can be 
computed and utilised for the prediction of a zig-zag crack growth path (Fig.17) that acts as a major source for the well-known crack closure phenomenon [31].

It would be ideal to have a direct comparison of the FE predictions with in-situ recording of fatigue crack growth trajectories, for which in-situ SEM/TEM with EBSD analyses are required, but no such results are currently available for the material studied in the present work. However, experimental evidence regarding the connection between crack growth path and slip planes (e.g., $\{111\},\{100\},\{110\})$ in f.c.c. materials has been well documented $[27$, $53,56,57]$. In this work, crack growth trajectories were explored based on the consideration of the maximum amount of accumulated shear deformation on the available slip planes. The crack growth follows either octahedral $\{111\}$ or cubic slip $\{100\}$ system, depending on the level of accumulated shear deformation for each slip system. The predicted crack growth trajectories seem to be highly dependent on the grain orientations, as shown here for two random distributions of grain structures (Figs.17a and b). Although no preferential slip planes may be identified from these results, both paths show macroscopically co-planar type of crack growth, which seems reasonable.

The present work utilised a micromechanics-based approach to study the crack tip deformation and crack growth path, which shows the influence of grain microstructure, although the results are specific to the set of orientation considered in the FE analyses. More substantial work is further required to thoroughly address the effect of grain orientation and size in damage tolerance design, including the correlation of crack growth rate with $\Delta \mathrm{K}$ and 
full simulation of crack growth. This was not attempted due to partly also the lack of vacuum test results which can remove the influence of oxidation that is known to be substantial for this alloy tested in air and at high temperature. As the crack growth was modelled as a series of stationary crack tips, the non-proportional loading and elastic unloading in the neighborhood of growing cracks in elastic-plastic solids were not captured in the present work, which can influence the slip band patterns near the crack tip and hence the crack path according to the current criterion adopted.

\section{Conclusions}

Crystal plasticity modelling of cyclic deformation has been presented for a polycrystalline nickel-based superalloy at elevated temperature. An RVE, consisting of a number of randomly oriented single crystal grains, has been constructed using the Voronoi tessellation and meshed for finite element analyses under periodic boundary constraints. The model parameters were determined from strain-controlled cyclic test data at $650^{\circ} \mathrm{C}$ for different loading rates using a fitting process. Simulations using fitted parameters showed good agreement with experimental data for stress-strain loops, cyclic hardening behaviour and stress relaxation behaviour during strain hold period.

Stress and strain contour plots of the deformed RVE showed heterogeneous distribution due to orientation mismatch between neighboring grains. Strain concentrations are basically located within soft grains, while stress concentrations are localized within hard grains. Localized inelastic deformation bands were also observed from the contour plot of 
accumulated inelastic strain, which seems to reside in the soft grains and may be the potential sites for fatigue crack nucleation.

The model was also applied to study the near-tip deformation for a transgranular crack in a CT specimen. Crack-tip deformation is shown to depend on the orientation of the grain at the crack tip, and the amount of accumulated slip near the crack tip varies according to the slip system which was further used as a criterion to predict crack growth path that follows the zig-zag route.

\section{Acknowledgements}

This work is funded by the EPSRC of the UK (grant EP/E062180/1) and in collaboration with Rolls-Royce plc (Dr Mark Hardy) and Cranfield University (Professor John Nicholls and Dr Nigel Simms) of the UK. LGZ acknowledges the support from the Royal Society and the Leverhulme Trust of the UK for a Senior Research Fellowship (10/2008 09/2009). The crystal plasticity UMAT was originally developed by Professor Esteban Busso and his associates while he was with the Imperial College, London.

\section{References}

[1] Zhao LG, Tong J, Byrne J. Finite element simulation of creep-crack growth in a nickel base superalloy. Engng Fract Mech 2001; 68:1157-1170.

[2] Zhao, LG, Tong J, Byrne J. The evolution of the stress-strain fields near a fatigue crack tip and plasticity-induced crack closure revisited. Fatigue Fract Engng Mater Struct 
$2004 ; 27: 19-29$.

[3] Zhan ZL. A study of cyclic plasticity and viscoplasticity in a new nickel-based superalloy using unified constitutive equations. Ph.D. thesis, University of Portsmouth; 2004.

[4] Dalby S, Tong J. Crack growth in a new nickel-based superalloy at elevated temperature, part I - effects of loading waveform and frequency on crack growth. J Mater Sci 2005; 40:1217-1228.

[5] Tong J, Dalby S, Byrne J. Crack growth in a new nickel-based superalloy at elevated temperature, part III - characterisation. J Mater Sci 2005; 40:1237-1243.

[6] Zhan ZL, Tong J. A study of cyclic plasticity and viscoplasticity in a new nickel-based superalloy using unified constitutive equations. Part I: evaluation and determination of material parameters. Mech Mater 2007; 39:64-72.

[7] Zhao LG, Tong J. A viscoplastic study of crack-tip deformation and crack growth in a nickel-based superalloy at elevated temperature. J Mech Phys Solids 2008; 56:3363-3378.

[8] Cornet C, Zhao LG, Tong J. Ratchetting Strain as a Damage Parameter in Controlling Crack Growth at Elevated Temperature. Engng Fract Mech 2009; 76:2538-2553.

[9] Zhao LG, Tong J, Hardy MC. Prediction of crack growth for a nickel-based suepralloy under fatigue-oxidation conditions. Engng Fract Mech 2010; 77:925-938.

[10] Kothari M, Anand L. Elasto-viscoplastic constitutive equations for polycrystalline metals: application to Tantalum. J Mech Phys Solids 1998; 46:51-83.

[11] Harder J. A crystallographic model for the study of local deformation processes in 
polycrystals. Int J Plast 1999; 15:605-624.

[12] Balasubramanian S, Anand L. Elasto-viscoplastic constitutive equations for polycrystalline fcc materials at low homologous temperatures. J Mech Phys Solids 2002; 20:101-126.

[13] Hasija V, Ghosh S, Mills MJ, Joseph D. Deformation and creep modeling in polycrystalline Ti-6Al alloys. Acta Mater 2003; 51:4533-4549.

[14] Zhang M, Zhang J, McDowell DL. Microstructure-based crystal plasticity modeling of cyclic defroamtion of Ti-6Al-4V. Int J Plast 2007; 23:1328-1348.

[15] Kovač M, Cizelj L. Modeling of elasto-plastic behaviour of polycrystalline grain structure of steels at mesoscopic level. Nucl Engng Des 2008; 235:1939-1950.

[16] Anand L. Single-crystal elasto-viscoplasticity: application to texture evolution in polycrystalline metals at large strains. Comput Meth Appl Mech Engng 2004; 193:5359-5383.

[17] Cheong KS, Smillie MJ, Knowles DM. Predicting fatigue crack initiation through image-based micromechanical modeling. Acta Mater 2007; 55:1757-1768.

[18] Dunne FPE, Walker A, Rugg, D. A systematic study of hcp crystal orientation and microphology effects in polycrystal deformation and fatigue. Proc R Soc London Ser A 2007; 463:1467-1489.

[19] Kirane K, Ghosh S. A cold dwell fatigue crack nucleation criterion for polycrystalline Ti-6242 using grain-level crystal plasticity FE model. Int J Fatigue 2008; 30:2127-2139.

[20] Dunne FPE, Wilkinson AJ, Allen R. Experimental and computational studies of low 
cycle fatigue crack nucleation in a polycrystal. Int J Plast 2007; 23:273-295.

[21] Shenoy M, Tjiptowidjojo Y, McDowell D. Microstructure-sensitive modeling of polycrystalline IN 100. Int J Plast 2008; 24:1694-1730.

[22] Lin B, Zhao LG, Tong J, Christ HJ. Crystal plasticity modelling of cyclic deformation of a polycrystalline nickel based superalloy at high temperature. Mater Sci Engng A 2010; A527: 3581-3587.

[23] Miller KJ. The behaviour of short fatigue cracks and their initiation. Part II-A general summary. Fatigue Fract Engng Mater Struct 1987; 10:93-113.

[24] Hussain K, De los Rios E, Navarro A. A two-stage micromechanics model for short fatigue cracks. Engng Fract Mech 1993; 44:425-436.

[25] Hussain K. Short fatigue crack behaviour and analytical models: a review. Engng Fract Mech 1997; 58:327-354.

[26] Tvergaard V, Wei Y, Hutchinson JW. Edge cracks in plastically deforming surface grains. Eur J Mech A - Solids 2001; 20:731-738.

[27] Zhai T, Wilkinson AJ, Martin JW. A crystallographic mechanism for fatigue crack propagation through grain boundaries. Acta Mater 2000; 48:4917-4927.

[28] King JE. Fatigue crack propagation in nickel-base superalloys - effects of microstructure, load ratio and temperature. Mater Sci Tech 1987; 3:750-764.

[29] Pang HT, Reed PAS. Fatigue crack initiation and short crack grwoth in nicekl-base turbine alloys - the effects of microstructure and operating parameters. Int J Fatigue $2003 ; 25: 1089-1099$. 
[30] Düber O, Künkler B, Krupp U, Christ H-J, Fritzen C-P. Experimental characterization and two-dimensional simulation of short-crack propagation in an austenitic-ferritic duplex steel. Int J Fatigue 2006; 28:983-992.

[31] Suresh S. Fatigue of Materials, Cambridge University Press; 1991.

[32] Gall K, Sehitoglu H, Kadioglu Y. Plastic zones and fatigue-crack closure under plane-strain double slip. Metall Mater Trans A 1996; 27A:3491-3501.

[33] Potirniche GP, Daniewicz SR. Analysis of crack tip plasticity for microstructurally small cracks using crystal plasticity theory, Engng Fract Mech 2003; 70:1623-1643.

[34] Potirniche GP, Daniewicz SR, Newman Jr. JC. Simulating small crack growth behaviour using crystal plasticity theory and finite element analysis. Fatigue Fract Engng Mater Struct 2004; 27:59-71.

[35] Simonovski I, Nilsson K-F, Cizelj L. The influence of crystallographic orientation on crack tip displacements of microstructurally small, kinked crack crossing the grain boundary. Comput Mater Sci 2007; 39:817-828.

[36] Lillbacka R, Johnson E, Ekh M. A model for short crack propagation in polycrystalline materials, Engng Fract Mech 2006; 73:223-232.

[37] Sreeramulu K, Sharma P, Narasimhan R, Mishra Raja K. Numerical simulations of crack tip fields in polycrystalline plastic solids. Engng Fract Mech 2010; 77:1253-1274.

[38] McDowell DL, Dunne FPE. Microstructure-sensitive computational modeling of fatigue crack formation. In J Fatigue 2010, 32: 1521-1542.

[39] Asaro RJ. Micromechanics of crystals and polycrystals. Adv Appl Mech 1983; 23:1-115. 
[40] Busso EP. Cyclic deformation of monocrystalline nickel alluminide and high temperature coatings. Ph.D. Thesis, Department of Mechanical Engineering, Massachusetts Institute of Technology, Cambridge, MA, USA; 1990.

[41] Busso EP, Meissonnier FT, O’Dowd NP. Gradient-dependent deformation of two-phase single crystals. J Mech Phys Solids 2000; 48:2333-2361.

[42] ABAQUS, Version 6.9. Hibbitt Karlsson and Sorensen, Inc., Providence, RI; 2009.

[43] Dennis RJ. Mechanistic modelling of deformation and void growth behaviour in superalloy single crystals. Ph.D. Thesis, Imperial College London, the UK; 2000.

[44] Meissonnier FT, Busso EP, O'Dowd NP. Finite element implementation of a generalized non-local rate-dependent crystallographic formulation for finite strains. Int J Plast 2001; 17:601-640.

[45] Stöcker C, Zimmermann M, Christ H-J, Zhan Z-L, Cornet C, Zhao LG, Hardy MC, Tong J. Microstructural characterisation and constitutive behaviour of alloy RR1000 under fatigue and creep-fatigue loading conditions. Mater Sci Engng A 2009; 518:27-34.

[46] Okabe A, Boots B, Sugihara K, Chiu SN. Spatial tessellations: concepts and: applications of Voronoi diagrams. 2nd Edition, John Wiley \& Sons Ltd, Chichester, UK; 2000.

[47] Smit RJM, Brekelmans WAM, Meijer HEH. Prediction of the mechanical behavior of nonlinear heterogeneous systems by multi-level finite element modeling. Comput Meth Appl Mech Engng 1998; 155:181-192.

[48] van der Sluis O, Schreurs PJG, Brekelmans WAM, Meijer HEH. Overall behaviour of heterogeneous elastoviscoplastic materials: Effect of microstructural modelling. Mech 
Mater 2000; 32:449-462.

[49] Bishop JFW, Hill R. Theory of plastic distortion of polycrystalline aggregate under combined stresses. Philos Mag 1951; 42:414-427.

[50] Chaboche JL. Constitutive equations for cyclic plasticity and cyclic viscoplasticity. Int J Plast 1989; 5:247-302.

[51] Crone WC, Shield TW. An experimental study of the effect of hardening on plastic deformation at notch tips in metallic singe crystals. J Mech Phys Solids 2003; 51:1623-1647.

[52] Crone WC, Shield TW, Creuziger A, Henneman B. Orientation dependence of the plastic slip near notches in ductile FCC single crystals. J Mech Phys Solids, 2004; $52: 85-112$

[53] Blochwitz C, Jacob S, Tirschler W. Grain orientation effects on the growth of short fatigue cracks in austenitic stainless steel. Mater Sci Engng A 2008; 496:59-66.

[54] Dunne FPE, Rugg D. On the mechanisms of fatigue facet nucleation in titanium alloys. Fatigue Fract Engng Mater Struct 2008; 31:949-958.

[55] Rice JR. Mechanics of crack tip deformation and extension by fatigue. In: Fatigue Crack Propagation, ASTM STP 415; 1967. p. 247-309.

[56] Gao Y, Stolken JS, Kumar M, Ritchie RO. High cycle fatigue of nickel base superalloy Rene 104 (ME3): interaction of microstructurally small cracks with grain boundaries of known character. Acta Mater 2007; 55:3155-3167.

[57] Blochwitz C, Richter R. Plastic strain amplitude dependent surface path of microstructurally short fatigue cracks in face-centred cubic metals. Mate Sci Engng A 
1999, 267:120-129. 


\section{Figure Captions}

Fig.1 Pole and inverse pole figures for a 150-grain RVE with one Euler angle ((a), (c) \& (e)) and three Euler angles ((b), (d) \& (f)).

Fig.2 (a) Grain texture for alloy RR1000, where the color designates crystallographic orientation [45]; (b) illustration of the RVE and periodic boundary conditions.

Fig.3 (a) Global finite element model for the CT specimen; (b) a 150-grain submodel with crack introduced across a couple of grains.

Fig.4 (a) Illustration of the grains enclosing the crack tip and (b) their inverse pole figure.

Fig.5 Comparison of simluated stress-strain loop and experimental results for the first cycle of a strain-controlled cyclic test (strain rate $\mathrm{d} \varepsilon / \mathrm{dt}=0.05 \% / \mathrm{s}$ and strain range $\Delta \varepsilon$ $=2 \%[6])$.

Fig.6 Comparison of simluated cyclic hardening and experimental results for a strain-controlled test (strain rate $\mathrm{d} \varepsilon / \mathrm{dt}=0.05 \% / \mathrm{s}$ and strain range $\Delta \varepsilon=2 \%[6]$ ).

Fig.7 Comparison of simluated stress-strain loop at saturation and experimental results for a strain-controlled cyclic test (strain rate $\mathrm{d} \varepsilon / \mathrm{dt}=0.05 \% / \mathrm{s}$ and strain range $\Delta \varepsilon=2 \%$ $[6])$. 
Fig.8 Comparison of model simulation and experimental data for the stress relaxation behaviour during 100-second dwells at maximum and minimum strain levels (strain rate $\mathrm{d} \varepsilon / \mathrm{dt}=0.5 \% / \mathrm{s}$ and strain range $\Delta \varepsilon=2 \%[3])$.

Fig.9 (a) Contour plot of the normal stress in the y-direction at the maximum strain level of the $25^{\text {th }}$ cycle (strain rate $\mathrm{d} \varepsilon / \mathrm{dt}=0.005 \% / \mathrm{s}$ and strain range $\Delta \varepsilon=2 \%$ ); (b) Inverse pole figure for the grians with high stress concentration.

Fig.10 (a) Contour plot of the normal strain in the y-direction at the maximum strain level of the $25^{\text {th }}$ cycle (strain rate $\mathrm{d} \varepsilon / \mathrm{dt}=0.005 \% / \mathrm{s}$ and strain range $\Delta \varepsilon=2 \%$ ); (b) Inverse pole figure for the grians with high strain concentration.

Fig.11 Stress-strain loops of individual grains for the 25 th laoding cycle (strain rate $\mathrm{d} \varepsilon / \mathrm{dt}=$ $0.005 \% / \mathrm{s}$ and strain range $\Delta \varepsilon=2 \%)$.

Fig.12 Contour plots of the von Mises stress obtained from the FE analyses using (a) crystal plasticity and (b) viscoplasticity model.

Fig.13 Comparison of the stress-strain response in the y-direction, averaged over a distance of $0.40 \mu \mathrm{m}$ ahead of the crack tip, for the crystal plasticity and viscoplasticity model. 
Fig.14 Comparison of the stress-strain response in the y-direction, averaged over a distance of $0.40 \mu \mathrm{m}$ ahead of the crack tip, for grain $1^{\prime}$ and $1^{\prime \prime}$.

Fig.15 (a) The 2D in-plane traces of the four slip systems with the most notable amount of accumulated shear deformation in four cycles; (b) Accumulated slip, averaged over a distance of $0.40 \mu \mathrm{m}$ ahead of the crack tip, as a function of the time for the four slip systems.

Fig.16 Illustration of slip traces with the maximum amount of accumulated slip for grain $1^{\prime}$ and $1^{\prime \prime}$.

Fig.17 Predicted crack growth paths for two submodels with different sets of random grain orientation.

Fig.18 Contour plot of the accumulated inelastic strain at the maximum strain level of the $25^{\text {th }}$ cycle (strain rate $\mathrm{d} \varepsilon / \mathrm{dt}=0.005 \% / \mathrm{s}$ and strain range $\Delta \varepsilon=2 \%$ ).

Fig.19 Contour plot of the von Mises equavalent strain at the maximum strain level of the $2^{\text {nd }}$ cycle (strain rate $\mathrm{d} \varepsilon / \mathrm{dt}=0.005 \% / \mathrm{s}$, strain range $\Delta \varepsilon=20 \%$, strain ratio $=-1$ ).

Fig.20 Influence of grain orientation on the maximum accumulated shear deformaiton averaged over a distance of $0.40 \mu \mathrm{m}$ ahead of the crack tip. 


\section{Table Caption}

Table 1, Fitted model parameters for alloy RR1000 at $650^{\circ} \mathrm{C}$. 


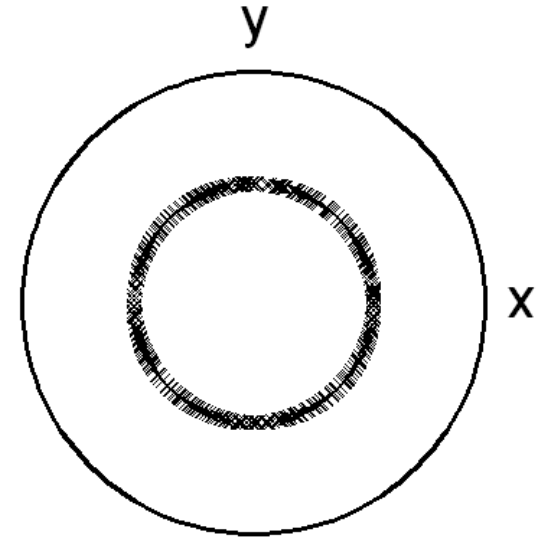

(a) $\{111\}$ pole figure

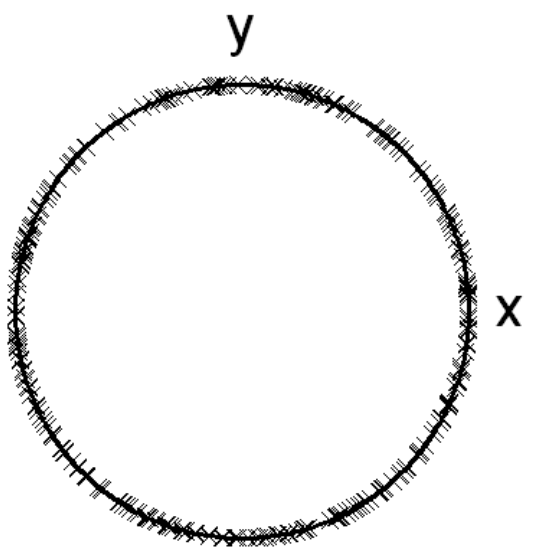

(c) $\{100\}$ pole figure

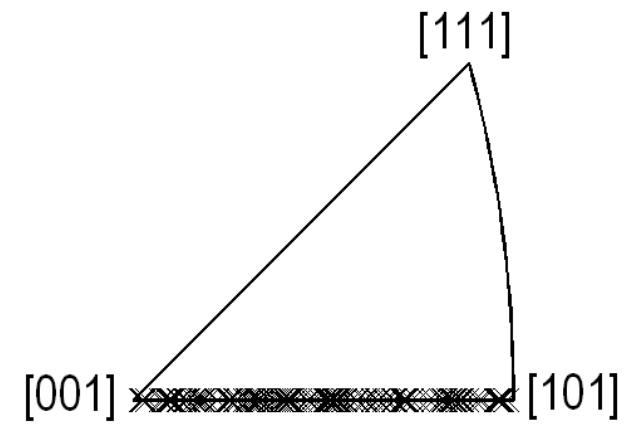

(e) $\sigma_{y y}-[010]$ inverse pole figure

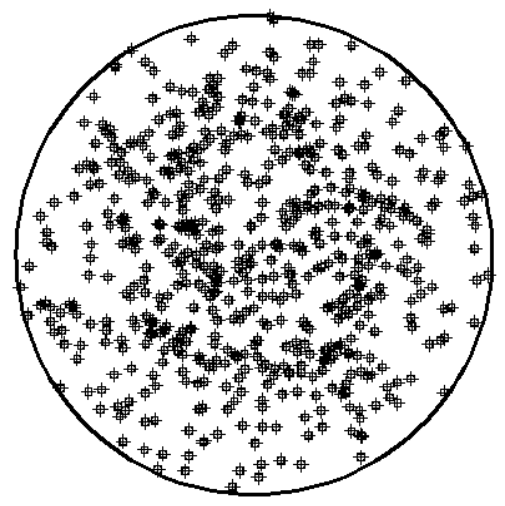

(b) $\{111\}$ pole figure

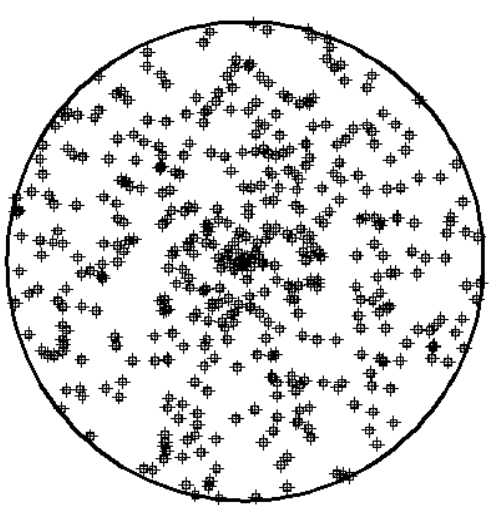

(d) $\{100\}$ pole figure

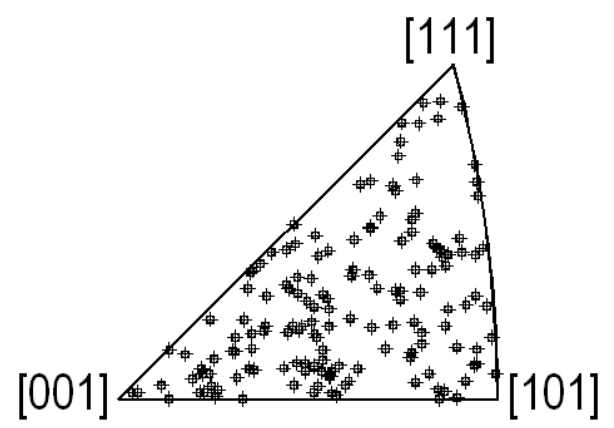

(f) $\sigma_{y y}-[010]$ inverse pole figure

Fig.1, Pole and inverse pole figures for a 150-grain RVE with one Euler angle ((a), (c) \& (e)) and three Euler angles ((b), (d) \& (f)). 
(a)

(b)

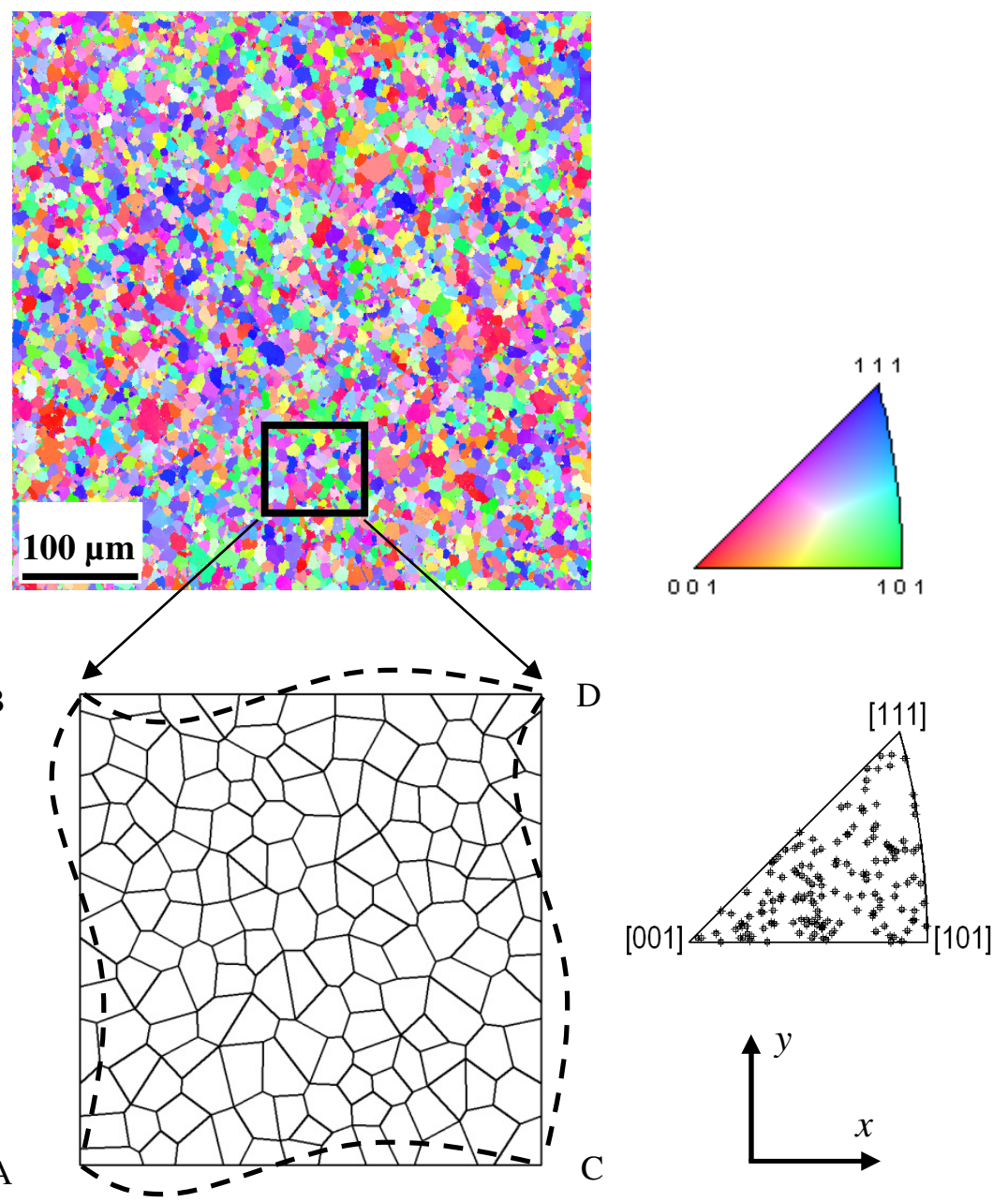

Fig.2, (a) Grain texture for alloy RR1000, where the color designates crystallographic orientation [45]; (b) illustration of the RVE and periodic boundary conditions. 
(a)

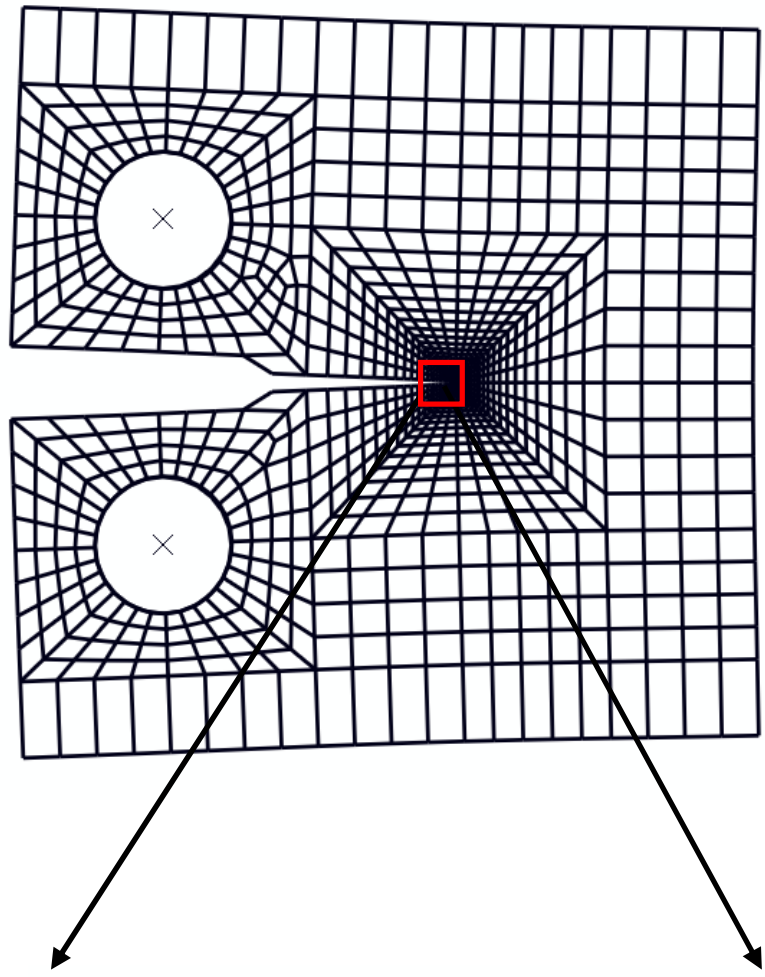

(b)

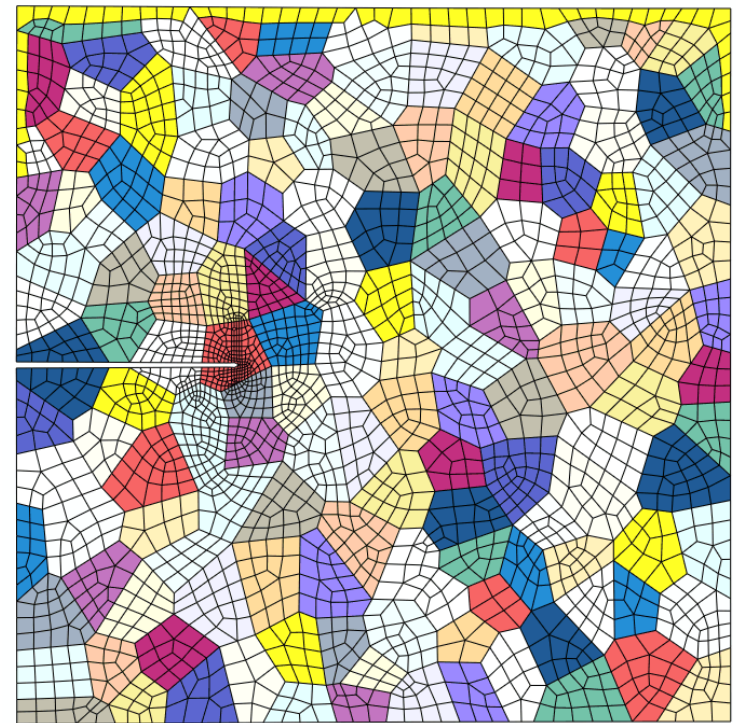

Fig.3, (a) Global finite element model for the CT specimen; (b) a 150-grain submodel with crack introduced across a couple of grains (mesh size near the crack tip is $\sim 0.20 \mu \mathrm{m}$ ). 
(a)

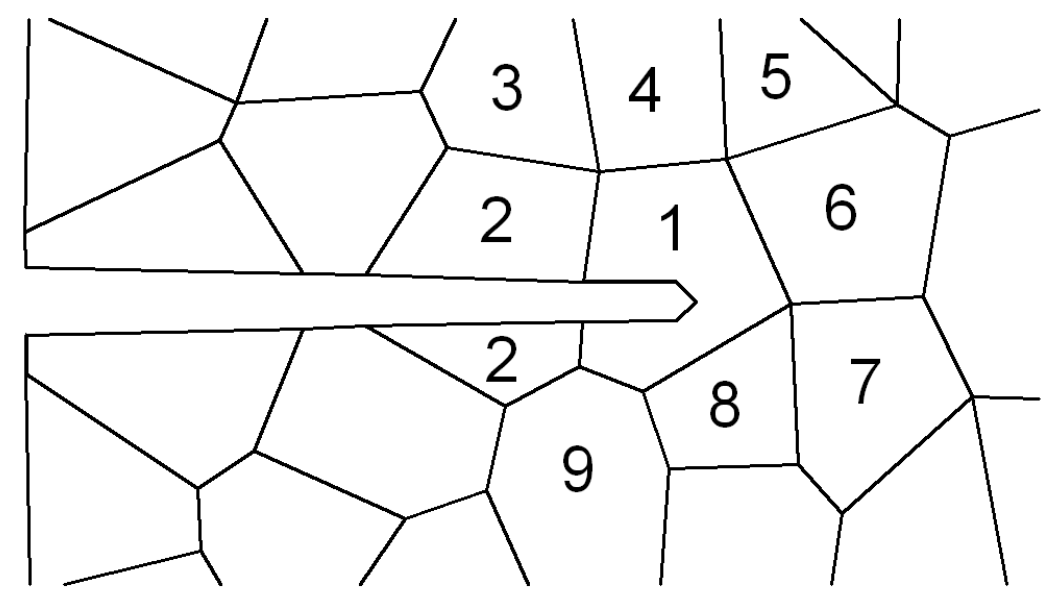

(b)

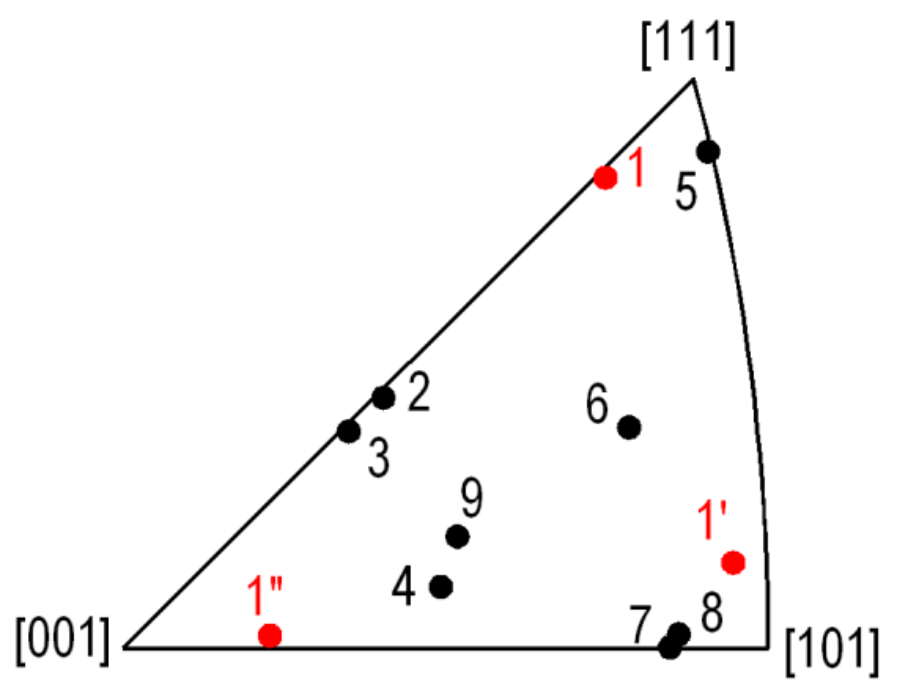

Fig.4, (a) Illustration of the grains enclosing the crack tip and (b) their inverse pole figure. 


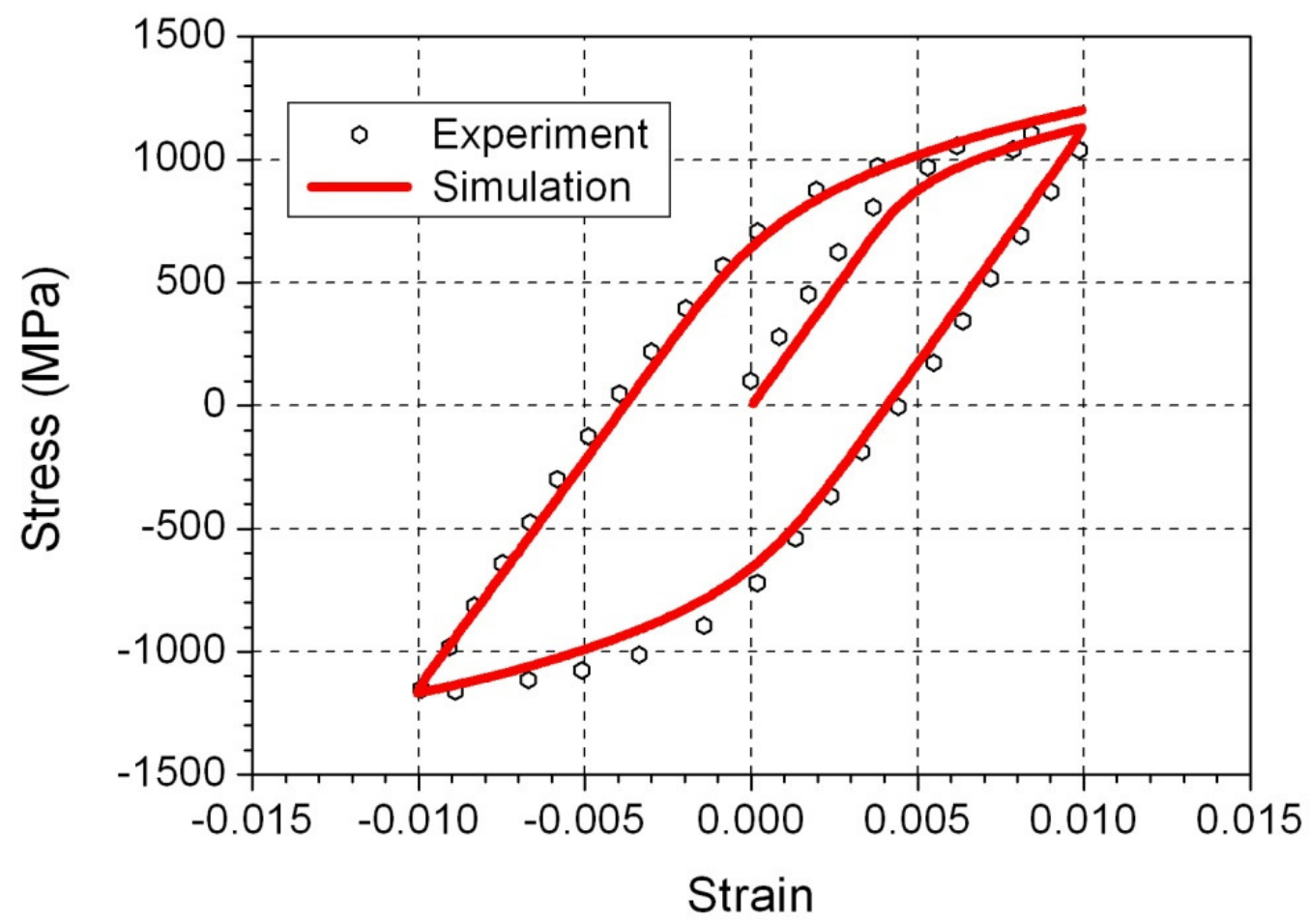

Fig.5, Comparison of simluated stress-strain loop and experimental results for the first cycle of a strain-controlled cyclic test (strain rate $\mathrm{d} \varepsilon / \mathrm{dt}=0.05 \% / \mathrm{s}$ and strain range $\Delta \varepsilon=2 \%[6]$ ). 


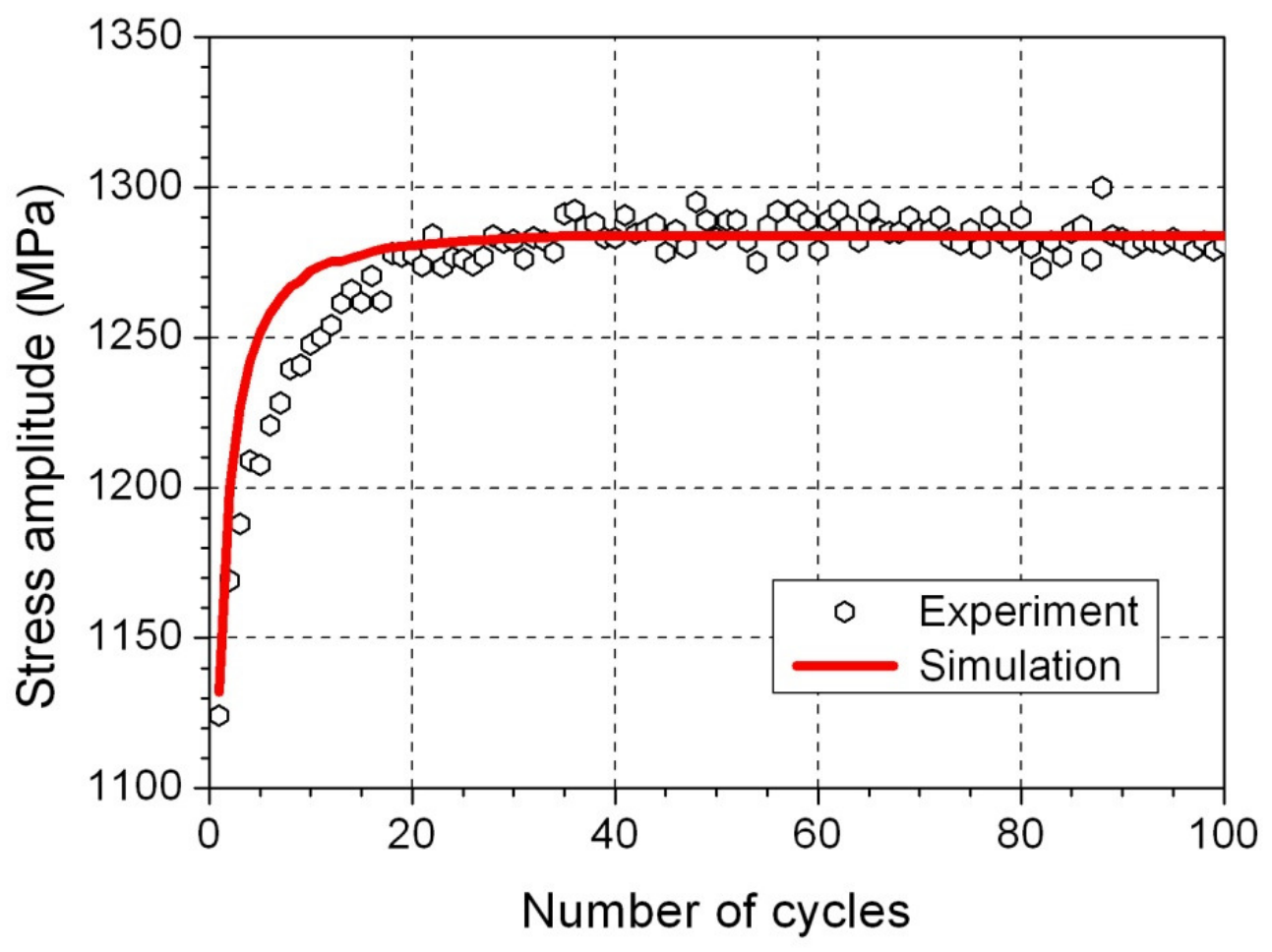

Fig.6, Comparison of simluated cyclic hardening and experimental results for a strain-controlled test (strain rate $\mathrm{d} \varepsilon / \mathrm{dt}=0.05 \% / \mathrm{s}$ and strain range $\Delta \varepsilon=2 \%[6]$ ). 


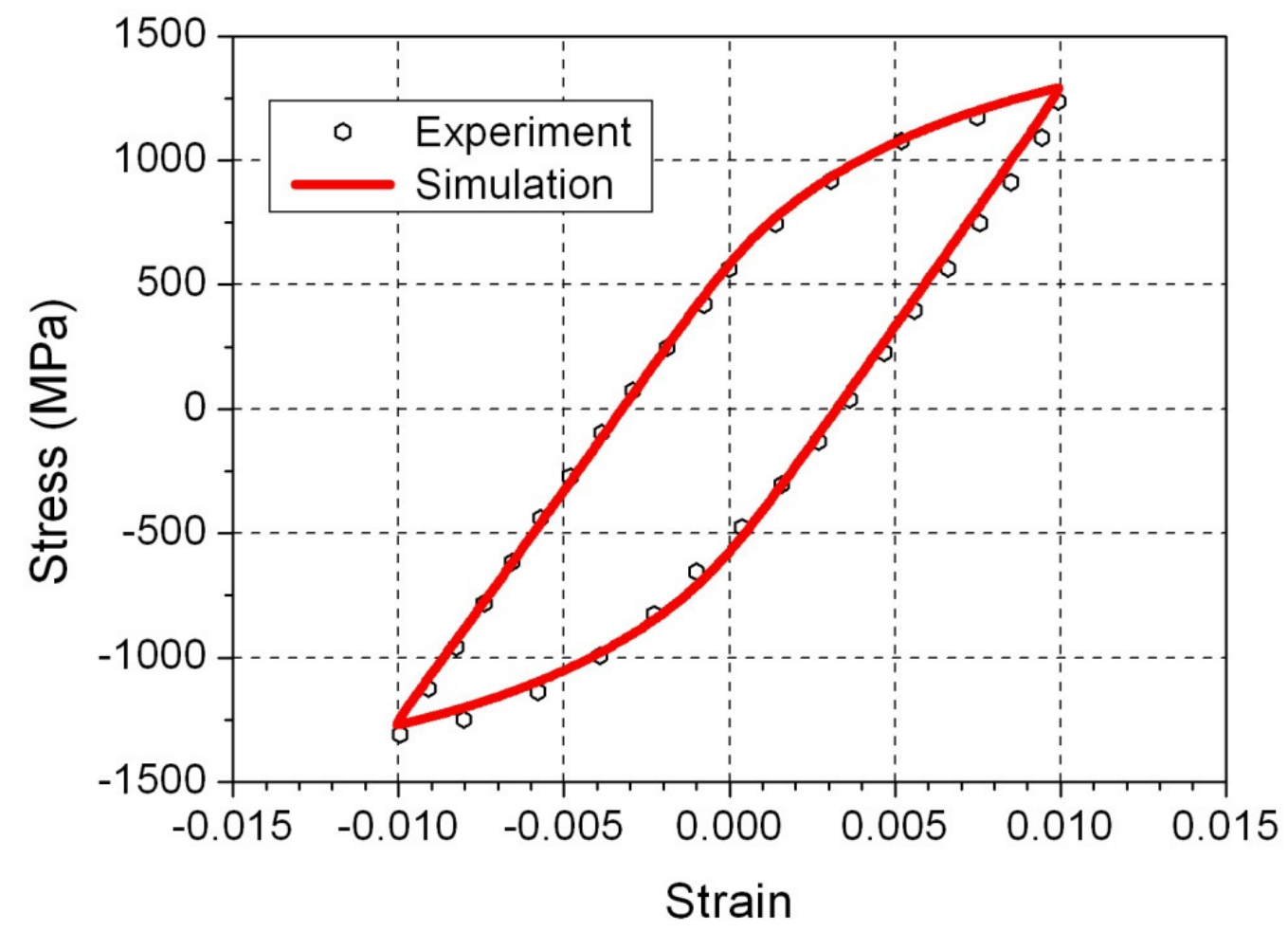

Fig.7, Comparison of simluated stress-strain loop at saturation and experimental results for a strain-controlled cyclic test (strain rate $\mathrm{d} \varepsilon / \mathrm{dt}=0.05 \% / \mathrm{s}$ and strain range $\Delta \varepsilon=2 \%[6]$ ). 


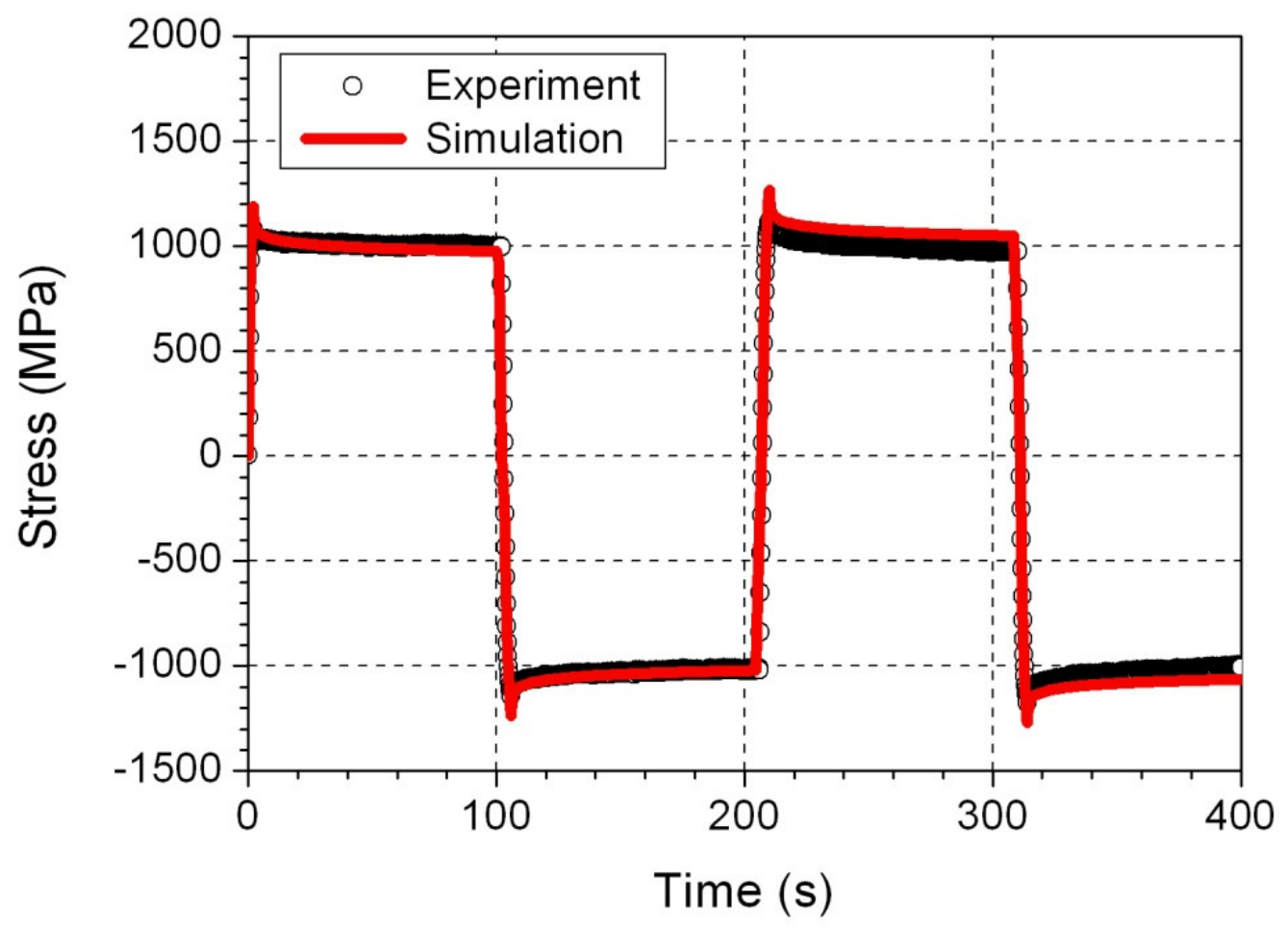

Fig.8, Comparison of model simulation and experimental data for the stress relaxation behaviour during 100-second dwells at maximum and minimum strain levels (strain rate de/dt $=0.5 \% / \mathrm{s}$ and strain range $\Delta \varepsilon=2 \%[3])$. 
(a)

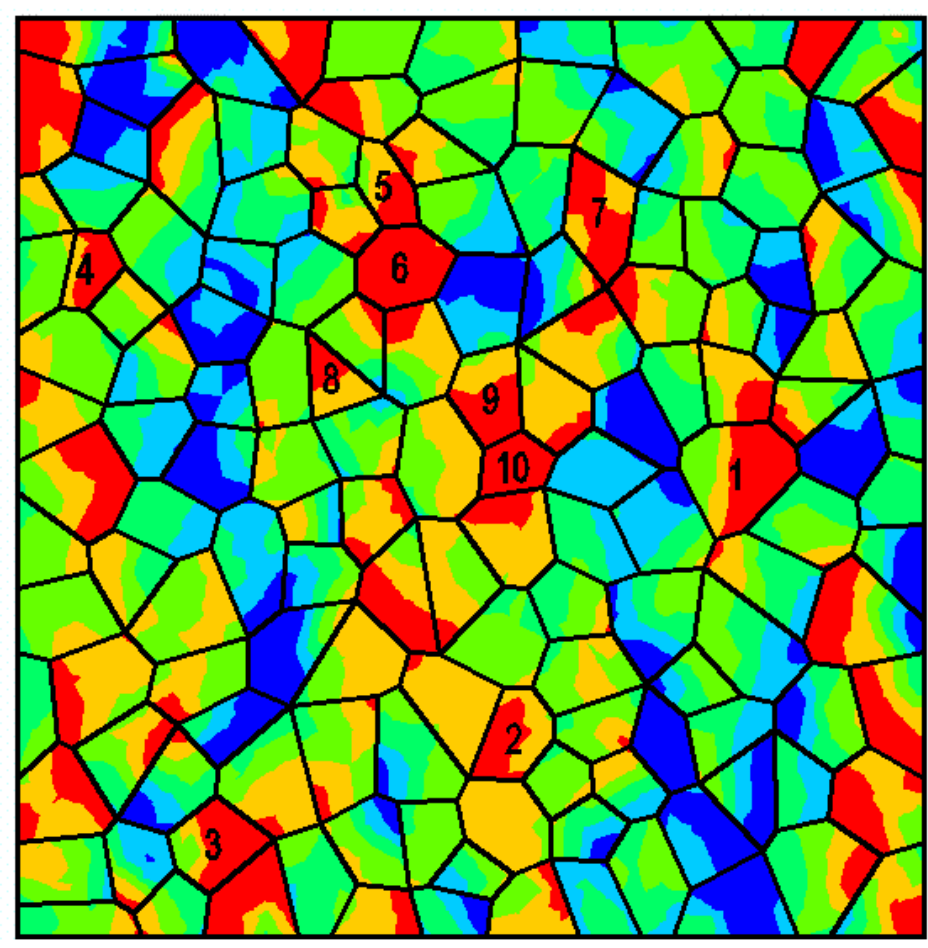

$\sigma_{\text {yy }}$

(Avg: 75\%)

- 1696.4

1460.0

1400.0

1340.0

1280.0

1220.0

1160.0

1100.0

902.2

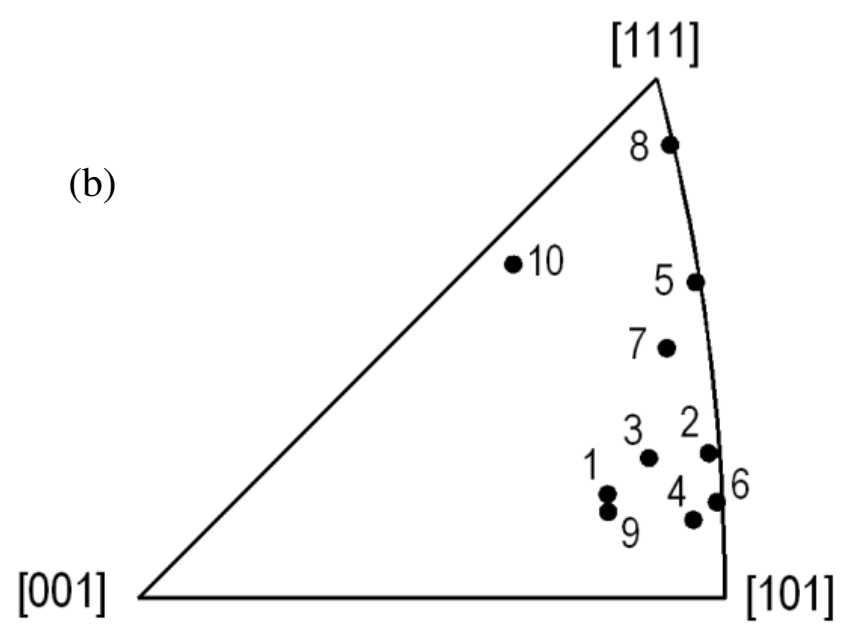

Fig.9, (a) Contour plot of the normal stress in the y-direction at the maximum strain level of the $25^{\text {th }}$ cycle (strain rate $\mathrm{d} \varepsilon / \mathrm{dt}=0.005 \% / \mathrm{s}$ and strain range $\Delta \varepsilon=2 \%$ ); (b) Inverse pole figure for the grians with high stress concentration. 
(a)

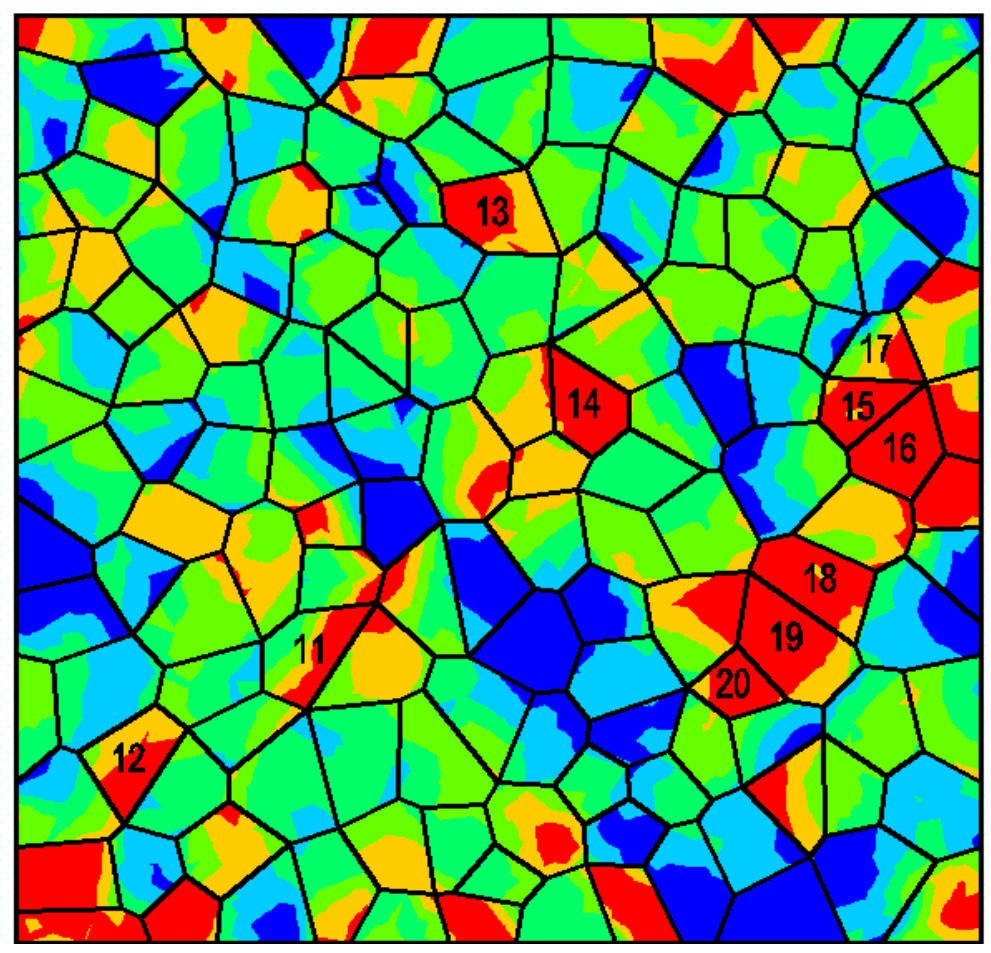

$\varepsilon_{\mathrm{yy}}$

(Avg: 75\%)

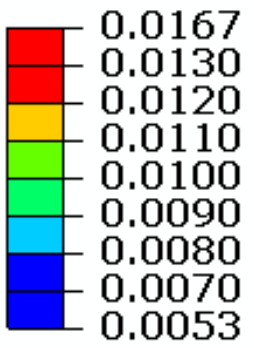

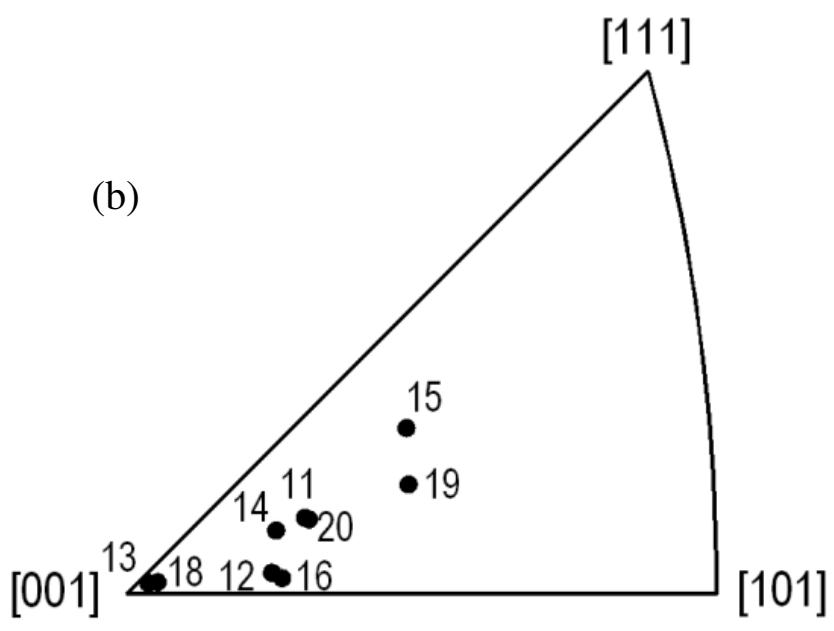

Fig.10, (a) Contour plot of the normal strain in the y-direction at the maximum strain level of the $25^{\text {th }}$ cycle (strain rate $\mathrm{d} \varepsilon / \mathrm{dt}=0.005 \% / \mathrm{s}$ and strain range $\Delta \varepsilon=2 \%$ ); (b) Inverse pole figure for the grians with high strain concentration. 


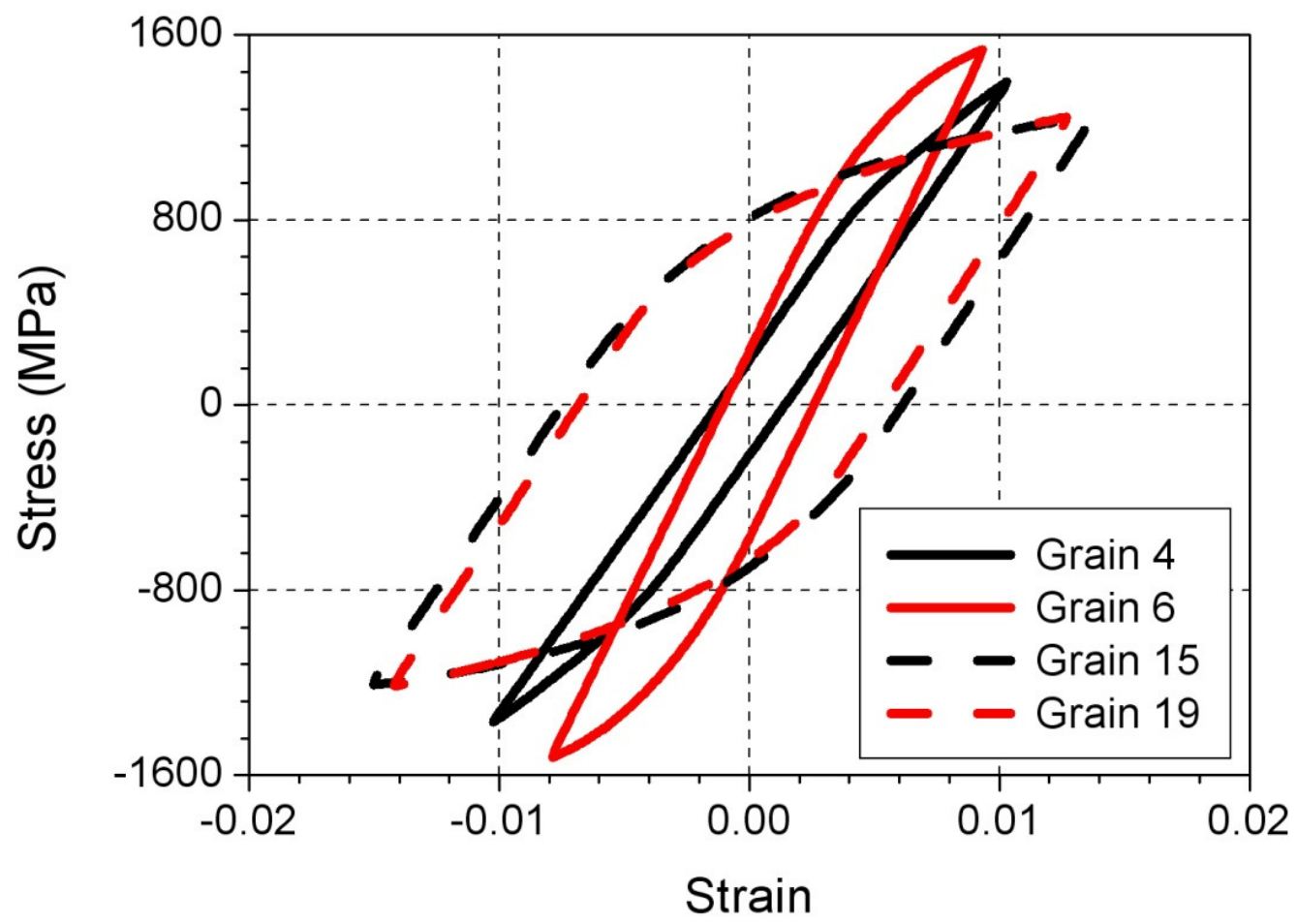

Fig.11, Stress-strain loops of individual grains for the 25 th laoding cycle (strain rate $\mathrm{d} \varepsilon / \mathrm{dt}=$ $0.005 \% / \mathrm{s}$ and strain range $\Delta \varepsilon=2 \%$ ). 
(a)

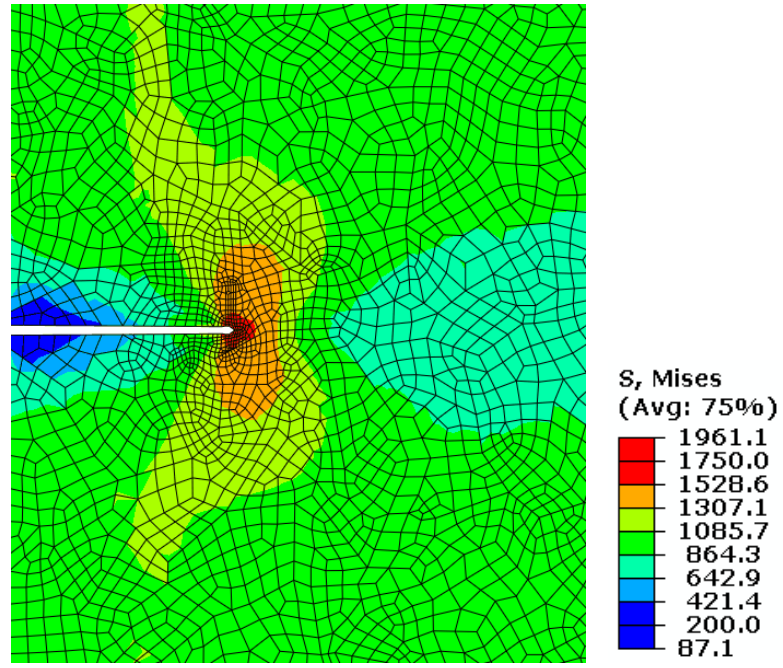

(b)

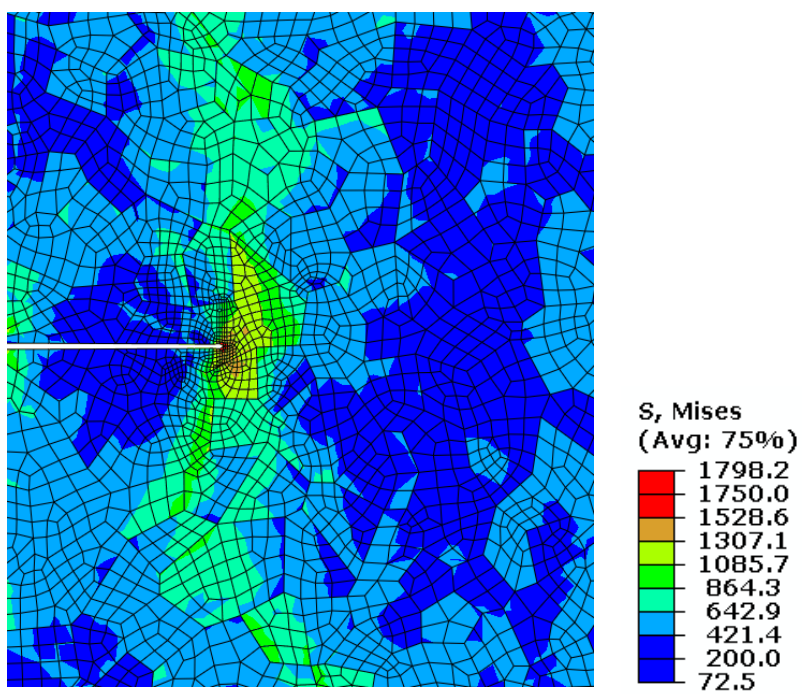

Fig.12, Contour plots of the von Mises stress obtained from the FE analyses using (a) viscoplasticity and (b) crystal plasticity model. 


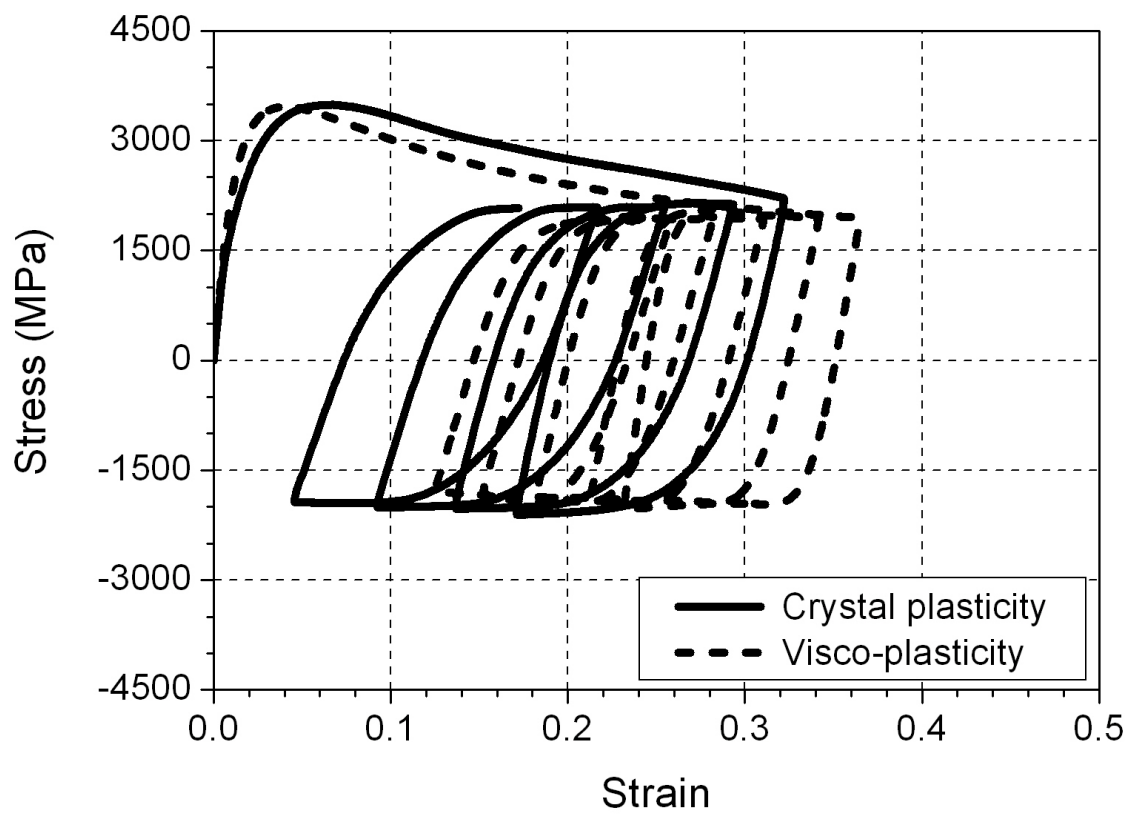

Fig.13, Comparison of the stress-strain response in the y-direction averaged over a distance of $0.40 \mu \mathrm{m}$ ahead of the crack tip for the crystal plasticity and viscoplasticity model. 


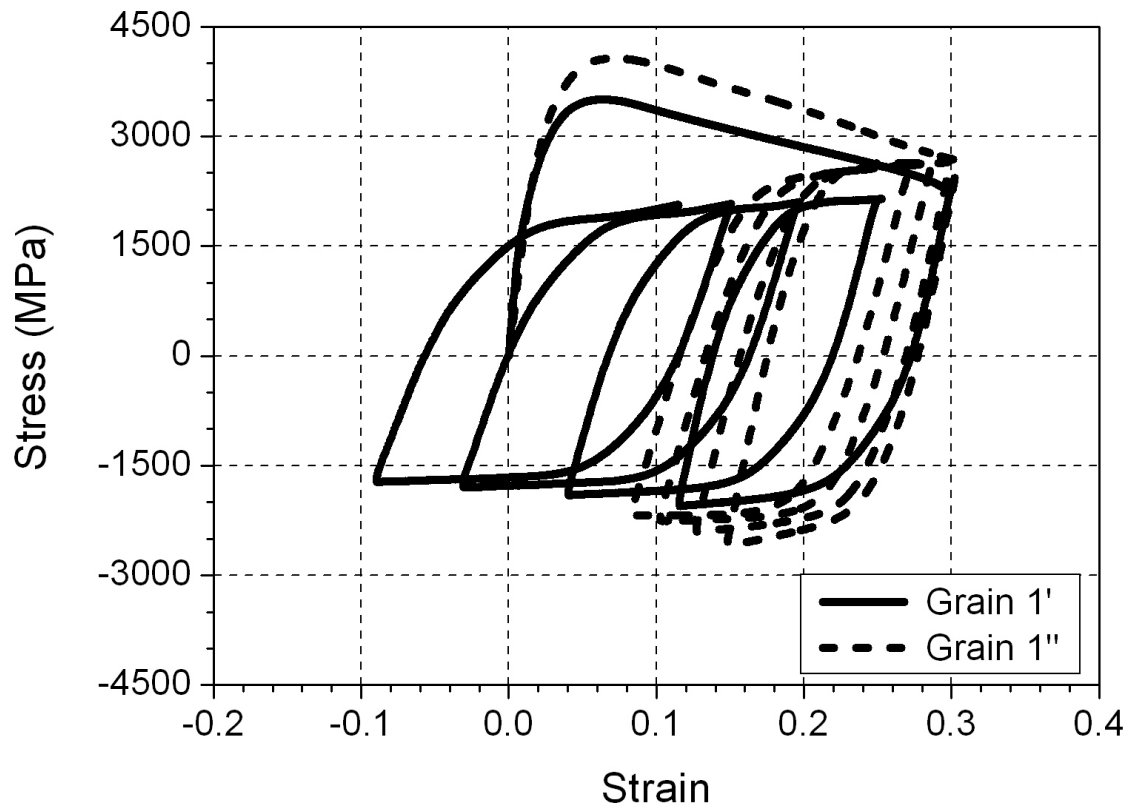

Fig.14, Comparison of the stress-strain response in the y-direction averaged over a distance of $0.40 \mu \mathrm{m}$ ahead of the crack tip for grain $1^{\prime}$ and $1^{\prime \prime}$. 
(a)

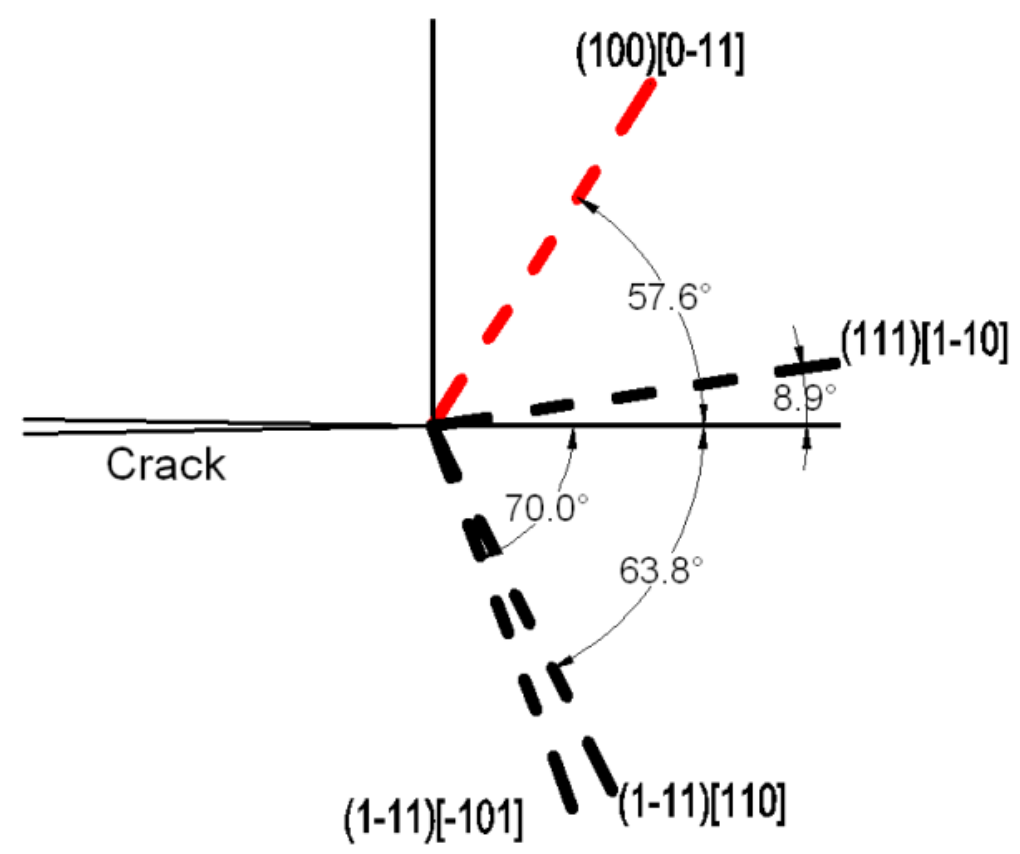

(b)

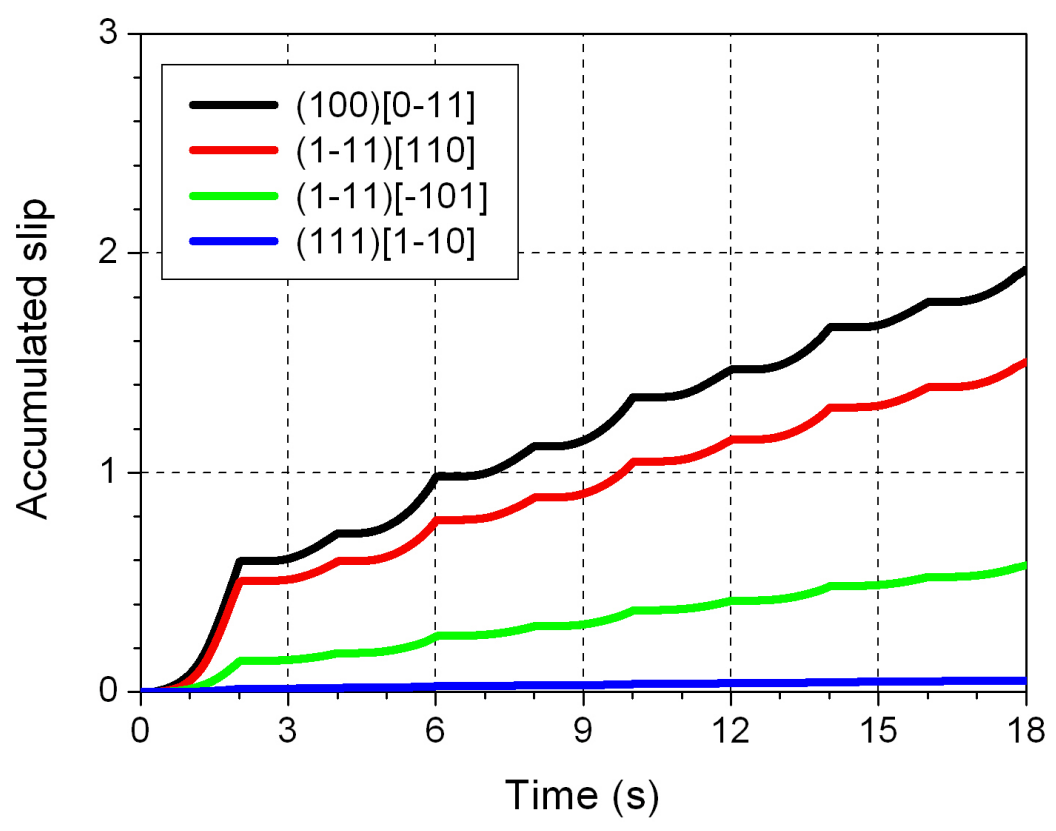

Fig.15, (a) The 2D in-plane traces of the four slip systems with the most notable amount of accumulated shear deformation in four cycles; (b) Accumulated slip, averaged over a distance of $0.40 \mu \mathrm{m}$ ahead of the crack tip, as a function of the time for the four slip systems. 


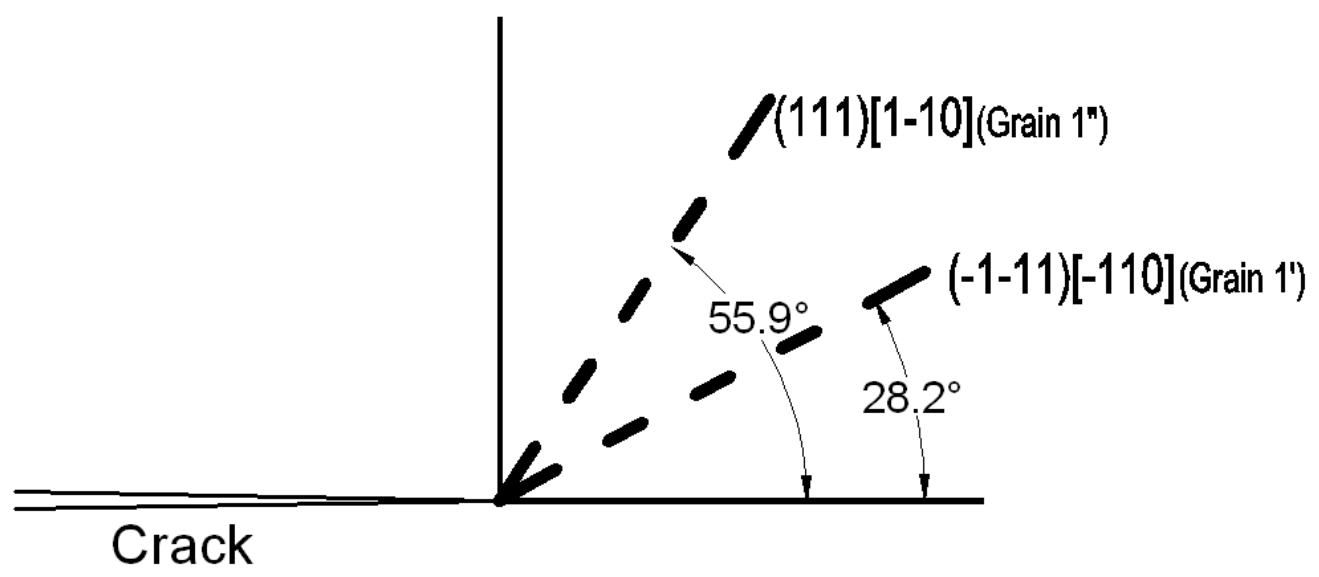

Fig.16, Illustration of slip traces with the maximum amount of accumulated slip for grain 1' and $1^{\prime \prime}$. 
(a)

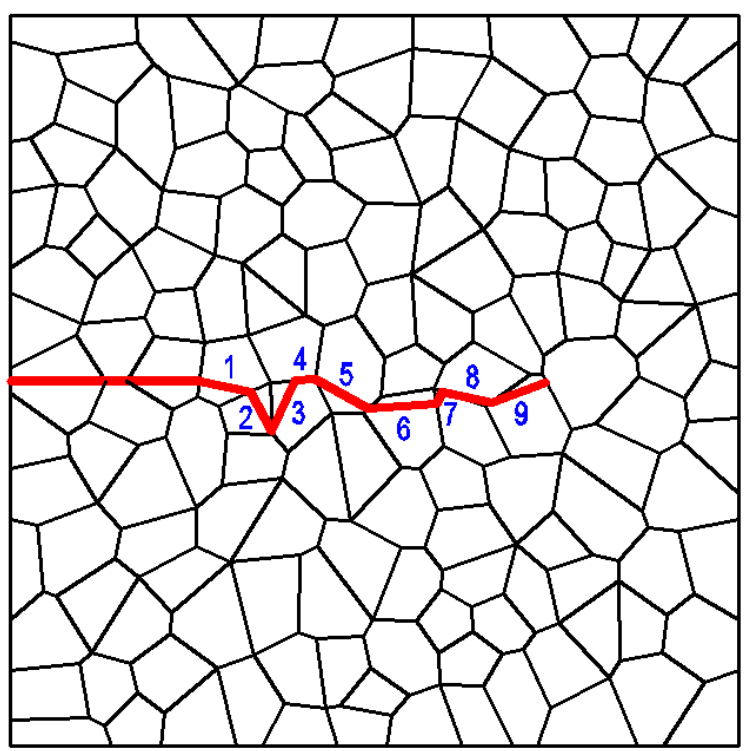

1: (100)[0-11]

2: (-111)[101]

3: (010)[-101]

4: (001)[-110]

5: (111)[1-10]

6: (1-11)[-101]

7: (111)[1-10]

8: (-111)[01-1]

9: $(-1-11)[-110]$

(b)

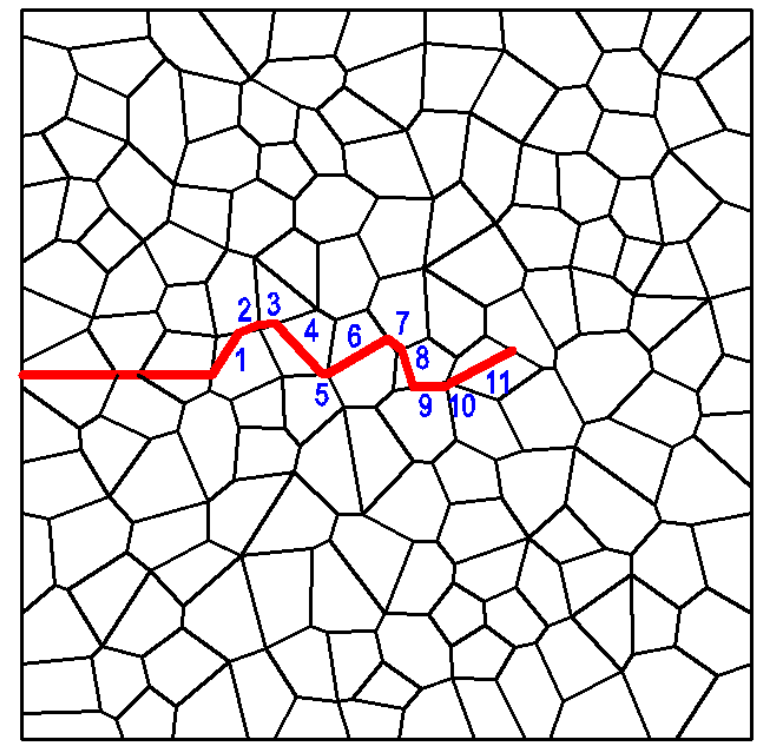

1: (100)[0-11]

2: (100)[0-11]

3: (001)[-110]

4: (1-11)[-101]

5: $(-111)[-1-10]$

6: (1-11)[110]

7: (100)[011]

8: (100)[011]

9: (-1-11)[101]

10: (1-11)[110]

11: (1-11)[110]

Fig.17, Predicted crack growth paths for two submodels with different sets of random grain orientation. 


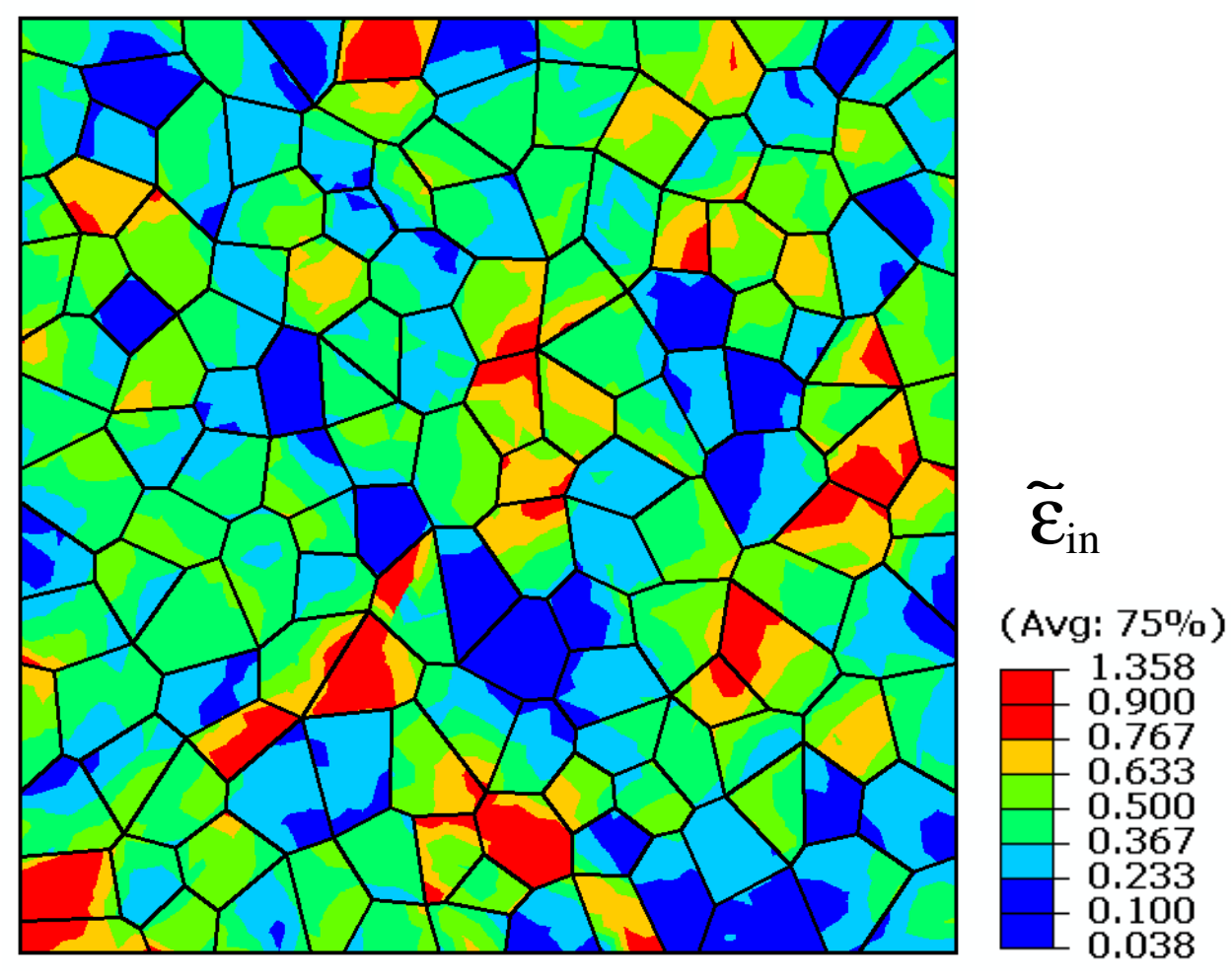

Fig.18, Contour plot of the accumulated inelastic strain at the maximum strain level of the $25^{\text {th }}$ cycle (strain rate $\mathrm{d} \varepsilon / \mathrm{dt}=0.005 \% / \mathrm{s}$ and strain range $\Delta \varepsilon=2 \%$ ). 


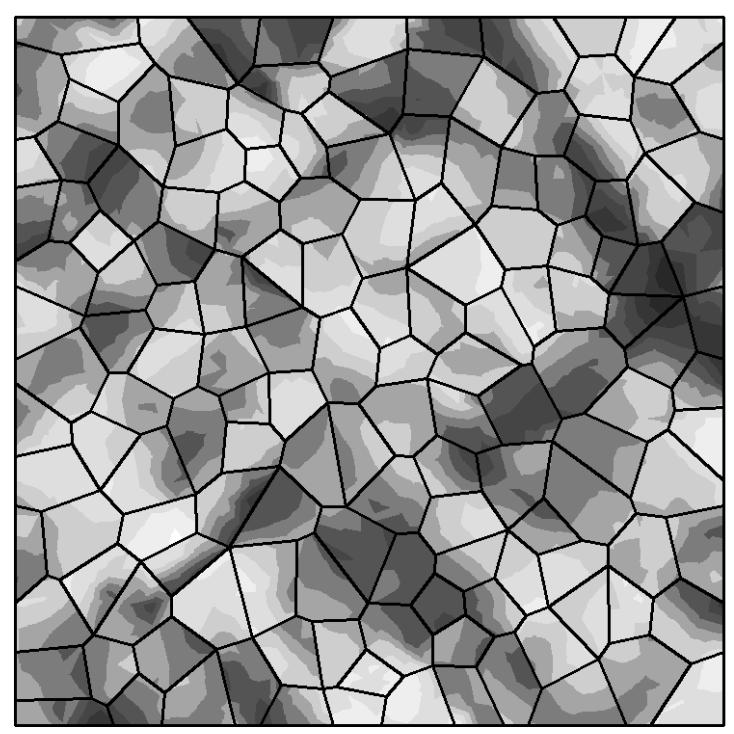

$\varepsilon_{\text {eq }}$

(Avg: 75\%)

0.27

0.25

0.22

0.19

0.16

0.14

0.11

0.08

0.05

0.03

0.00

Fig.19, Contour plot of the von Mises equavalent strain at the maximum strain level of the $2^{\text {nd }}$ cycle $($ strain rate $\mathrm{d} \varepsilon / \mathrm{dt}=0.005 \% / \mathrm{s}$, strain range $\Delta \varepsilon=20 \%$, strain ratio $=-1$ ). 


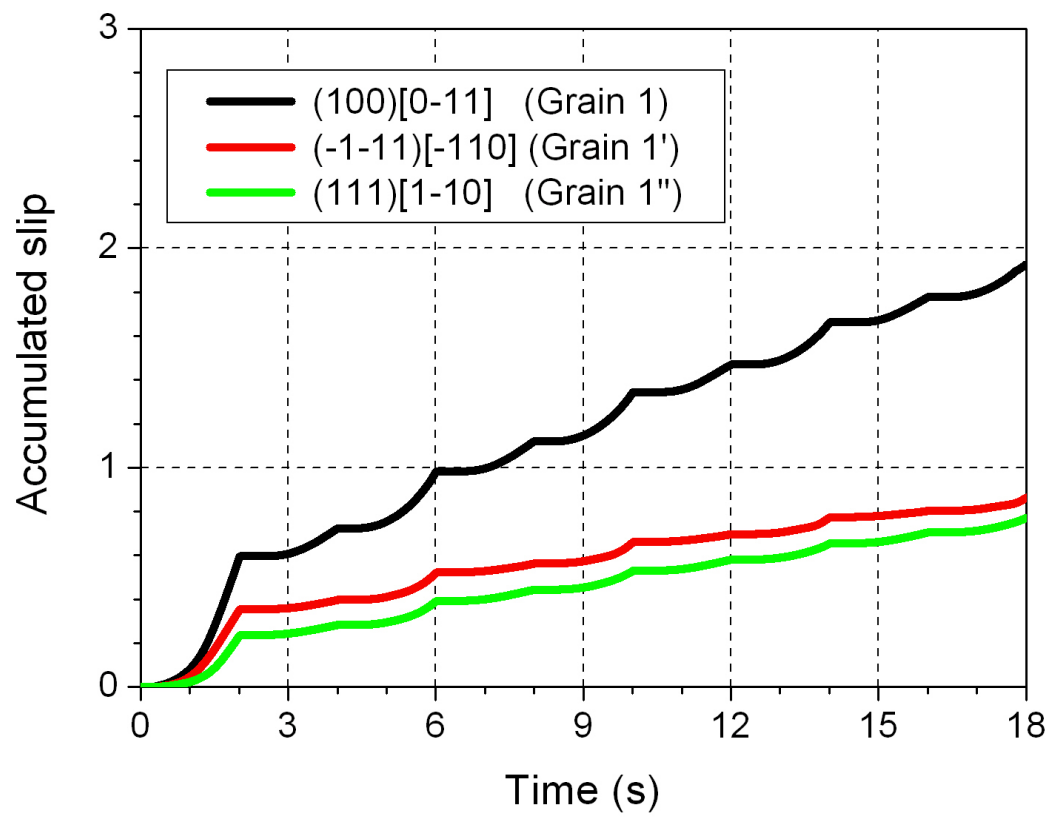

Fig.20, Influence of grain orientation on the maximum accumulated shear deformaiton averaged over a distance of $0.40 \mu \mathrm{m}$ ahead of the crack tip. 